\title{
CONSIDERACIÓN Y TRATAMIENTO DE LOS PAISAJES AGRARIOS EN LOS INSTRUMENTOS DE PROTECCIÓN AMBIENTAL, ORDENACIÓN TERRITORIAL Y PLANEAMIENTO URBANÍSTICO. CANTABRIA (ESPAÑA) COMO CASO DE ESTUDIO'
}

\author{
Carmen Delgado Viñas \\ Grupo de Investigación "Dinámica territorial de los espacios rurales" \\ Departamento de Geografía, Urbanismo y Ordenación del Territorio. Universidad de Cantabria \\ delgadoc@unican.es
}

\section{RESUMEN}

Bajo el enfoque del Convenio Europeo del Paisaje y desde una perspectiva territorial, en esta investigación se ha analizado la normativa autonómica y municipal de Cantabria sobre los espacios rurales con la finalidad de conocer qué normas y documentos abordan el paisaje rural, y en particular los paisajes agrarios, y, cuando los tratan, averiguar qué valores y tratamiento se les está dando (medioambiental, económico, cultural, patrimonial...). En términos generales, hasta ahora la mayor parte de los documentos analizados apenas se han ocupado de los paisajes y menos aún de los paisajes rurales cotidianos. En el mejor de los casos, la primacía corresponde a las actuaciones indirectas, a través de la gestión del Suelo Rústico de Especial Protección bajo tres enfoques complementarios o alternativos, productivo, ambiental y visual, destacando cada vez en mayor medida el interés por el posible aprovechamiento económico del paisaje.

Palabras clave: Paisaje rural, Paisaje agrario, Planificación espacial, Planeamiento urbanístico, Protección ambiental, Cantabria.

Fecha de recepción: abril 2016.

Fecha de aceptación: mayo 2017.

1 Este trabajo se inscribe en el marco del Proyecto de Investigación "Paisajes culturales de la Lista Patrimonio Mundial. Claves para la identificación y criterios para la gestión de paisajes agroganaderos, mineros e industriales de la España Atlántica.”, Plan Nacional I+D+I 2016-2019, Proyectos de Investigación Fundamental no orientada, Proyectos Coordinados CSO2015-65787-C6-3-P. Sobre este mismo aspecto la autora ha publicada ya dos textos, mucho más breves y limitados temática y temporalmente, que pueden considerarse como precursores del actual (Delgado Viñas, 2014b y 2015). 


\section{ABSTRACT}

From the conceptual approach of the European Landscape Convention and under a territorial perspective, this research has analysed the autonomous and municipal regulations of Cantabria on rural areas in order to know what rules and documents deal with the rural landscape, and in particular agricultural landscapes, and, when they are treated, to find out what values and meanings they are being given (environmental, economic, cultural, heritage...). In general terms, most of the documents analysed have so far hardly dealt with landscapes, let alone everyday rural landscapes. In the best of cases, the primacy corresponds to indirect actions, through the management of the Special Protection Rustic Land under three complementary or alternative approaches, productive, environmental and visual, emphasizing increasingly interest in the possible economic use of the landscape.

Keywords: Rural landscape, Agrarian landscape, Land management, Urban planning, Environmental protection, Cantabria.

\section{INTRODUCCIÓN}

La finalidad de la investigación en que se apoya este artículo es analizar el tratamiento que dan a los paisajes agrarios los instrumentos de planificación y gestión del territorio que se ocupan de su protección y ordenación, directa o indirectamente. Para ello se ha llevado a cabo el estudio de la Comunidad de Cantabria cuyas instituciones autonómicas y municipales ejercen las competencias en tal materia, por lo que son las escalas regional y local las que se han utilizado preferentemente para acometer el análisis.

Bajo diferentes enfoques, está temática está empezando a ser objeto de atención de numerosos investigadores, procedentes del campo de la Geografía en gran medida. Así, desde una perspectiva general, los estudios de Bertrand (1994), Mata Olmo y Tarroja i Coscuela (2006), Agudo González (2007), Silva Pérez (2010), Gómez Mendoza (2013), Castillo y Martínez (2014) y Zoido Naranjo (2015), entre otros. Algunos investigadores se han aproximado a este aspecto desde ámbitos territoriales específicos, como es el caso de Cañete Pérez (2015) para Andalucía, García y Borobio (2012) para Galicia, Mata Olmo et alii (2012) y Delgado Viñas (2014b y 2015) para Cantabria. La problemática concreta de los paisajes agrarios periurbanos ha sido abordada por Delgado Bujalance (2009) o Simón, Zazo y Morán (2012). Otros autores han analizado la relación entre paisajes agrarios y espacios naturales protegidos, como lo han hecho Español Echaniz (2010), Mulero Mendigorri (2013) y Sánchez del Árbol (2015).

En el estudio actual, que incorpora algunas de las ideas y conclusiones alcanzadas en sus respectivas investigaciones por autores citados antes, se ha pretendido realizar una aproximación profunda y bajo diferentes enfoques al tratamiento de los paisajes agrarios en los documentos de ordenación territorial y planificación urbanística de la Comunidad cántabra, considerada como un caso de estudio con resultados extrapolables, tanto por lo que se refiere a sus espacios rurales periurbanos, situados por lo general en el área litoral, como a los espacios profundamente rurales, localizados casi siempre en las áreas montañosas del interior de la región. 
Desde un punto de vista metodológico la investigación se ha apoyado principalmente en la prospección documental y, complementariamente, en la consulta de la bibliografía afín a los aspectos considerados. Se ha recurrido, además, al estudio comparativo de fotografías aéreas de diferentes fechas, a mapas de usos del suelo, a la prensa periódica nacional y regional y a los datos de la evolución poblacional y la dinámica inmobiliaria utilizados como indicadores de los cambios territoriales acaecidos en las últimas décadas.

Por lo que se refiere a los paradigmas básicos, el punto de partida ha sido la consideración de la indiscutible exigencia de la protección y gestión de los espacios y los paisajes rurales por motivos socioculturales, pero también por causas económicas inherentes a su consideración como recursos fundamentales para el desarrollo sostenible de estos territorios, como han afirmado reiteradamente competentes autores y documentos oficiales (Mata Olmo, 2006, Título V del Programa de Declaración de la Reserva de la Biosfera de la Isla de Menorca). Entre estos últimos, y de forma esencial, el Convenio Europeo del Paisaje (Consejo de Europa, 2000) que, aunque no sea propiamente una normativa de planificación espacial, suele servir de referencia en los documentos que se han elaborado para los espacios rurales en los años transcurridos del siglo XXI, siguiendo la recomendación de "integrar el paisaje en las políticas de ordenación territorial y urbanística”. En dicho Convenio se reconoce la especificidad del paisaje, más allá de otras razones ambientales o culturales, como una herramienta útil para la planificación y gobernanza territorial (Español Echániz, 2010; García y Borobio, 2012; Zoido Naranjo, 2015).

\section{LOS PAISAJES RURALES EN EL MARCO LEGISLATIVO CON INCIDENCIA EN CANTABRIA}

Aunque de forma indirecta, a escala estatal se encuentran referencias al paisaje rural en la Ley 42/2007 del Patrimonio Natural y de la Biodiversidad, la Ley 45/2007 de Desarrollo Sostenible del Medio Rural, la Ley del Suelo, 8/2007, de 28 de mayo, y el Real Decreto Legislativo 2/2008 por el que se aprueba el texto refundido de la Ley del Suelo.

La Ley 8/2007 parte de la consideración de que "todo el suelo rural tiene un valor ambiental digno de ser ponderado, por lo que propugna la clasificación responsable del suelo urbanizable necesario para atender las necesidades económicas y sociales" (Delgado Viñas, 2010). La aplicación de este principio supone una mutación radical con respecto a la anterior concepción del "Suelo no Urbanizable" contenida en la Ley 6/1998 y, además, exige especial protección de los terrenos rústicos "por los valores en ellos concurrentes, incluso los ecológicos, agrícolas, ganaderos, forestales y paisajísticos" ". Asimismo, en el artículo dedicado a exponer los "Principios de desarrollo territorial y urbano sostenible", se obliga a procurar "La eficacia de las medidas de conservación y mejora de la naturaleza, la flora y la fauna y de la protección del patrimonio cultural y del paisaje" (Título Preliminar, art'. 2 , 2.a.) ${ }^{3}$.

A diferencia de algunos países (entre otros el caso de Francia, que promulgó una Ley de Protección y Valorización de los Paisajes en 1993), en España la normativa sobre este aspecto ha tenido hasta ahora un escaso desarrollo ya que, si bien el gobierno español firmó el Con-

2 Todos los subrayados de aquí en adelante han sido realizados por la autora.

3 Esta normativa fue incorporada a la legislación autonómica por medio de la Ley de Cantabria 7/2007, de 27 de diciembre, de Medidas Fiscales y de Contenido Financiero. 
venio Europeo del Paisaje el mismo año de su aprobación y lo ha ratificado en noviembre de 2007 (BOE $n^{\circ} 31$ de 5 de febrero de 2008), no se ha promulgado ninguna ley estatal sobre paisajes y son muy pocas las Comunidades Autónomas que tienen aprobados documentos normativos en esta materia ${ }^{4}$, a pesar de que son éstas las entidades político-administrativas que poseen las competencias de ordenación del territorio (artículos 24.3 y 25.7 del Estatuto de Autonomía en el caso de Cantabria).

En el caso concreto de Cantabria, recientemente se ha elaborado la Ley de Cantabria del Paisaje, aprobada en diciembre de $2014^{5}$. En su preámbulo, la Ley alude al hecho de que "El paisaje ha ido adquiriendo paulatinamente una mayor relevancia social y ambiental" y a la necesidad de que "las administraciones públicas introduzcan criterios paisajísticos en sus actuaciones [...] Se trata por lo tanto no solo de proteger el Paisaje, sino sobre todo de gestionarlo adecuadamente". Entre los objetivos figura el de "Integrar plenamente el paisaje en el planeamiento y en las políticas de ordenación territorial y urbanística, así como en las demás políticas sectoriales que inciden en el mismo de forma directa o indirecta" (art ${ }^{\circ}$. 5.d.).

La Ley, asimilando los conceptos contenidos en el Convenio Europeo del Paisaje, se refiere "tanto a los paisajes rurales, urbanos y periurbanos que puedan considerarse excepcionales como a los paisajes cotidianos y a los degradados" ( $\left.\operatorname{art}^{\circ} .2\right)$. Aunque sin referencia específica a los paisajes agrarios, éstos quedan incluidos implícitamente en la definición legal de "Protección de los paisajes: las acciones encaminadas a conservar y mantener los aspectos significativos o característicos de un paisaje, justificados por su valor patrimonial derivado de su configuración natural y/o la acción del hombre" ( art $^{\circ}$. 3.f.). Igualmente cuando se plantea el objetivo de fomentar "la difusión de los valores de los paisajes de Cantabria en tanto que resultado de una construcción social histórica en permanente evolución" ( $\operatorname{art}^{\mathrm{o}}$. 7.2).

Con vistas a la ordenación paisajística, se establecen doce ámbitos identificados como "las grandes unidades de paisaje a escala regional, a partir de las cuales, se pueden definir unidades de paisaje a escala local" ( $\operatorname{art}^{\circ} .10 .1$ y 2), bien es verdad que sin mayor definición ni explicación de los criterios empleados para la definición de dichos ámbitos ni de los caracteres paisajísticos específicos que justifican tal clasificación.

Entre las herramientas de aplicación, la Ley propone los "Proyectos de Actuación Paisajística", los "Proyectos de Restauración de Paisajes Degradados" y los instrumentos de “Análisis de Impacto e Integración Paisajística”. En la Ley se establecen, como instrumen-

4 Comunidad Autónoma Valenciana: Ley 4/2004, de 30 de junio, de Ordenación del Territorio y Protección del Paisaje. (DOGV 4788, de 2 de julio de 2004), Decreto 120/2006, de 11 de agosto, por el que se aprueba el Reglamento de Paisaje de la Comunitat Valenciana (DOGV 5.325 de 16 de agosto de 2006) y Ley 5/2014, de 25 de julio, de Ordenación del Territorio, Urbanismo y Paisaje, de la Comunitat Valenciana. Comunidad Autónoma de Cataluña: Ley 8/2005, de 8 de junio, de Protección, Gestión y Ordenación del Paisaje (DOGC 4407, de 16 de junio de 2005) y Decreto 343/2006, de 19 de septiembre, por el que se desarrolla la Ley 8/2005 y se regulan los estudios e informes de impacto e integración paisajística. (DOGC 4723, de 21 de septiembre de 2006). Comunidad Autónoma de Galicia: Ley 7/2008, de 7 de julio, de Protección del Paisaje de Galicia (DOG 139, de 18 de julio de 2008). El 16 de junio del 2014 se publicó el Decreto 90/2014, de 3 de junio, sobre protección, gestión y ordenación del paisaje en la ordenación del territorio de la Comunidad Autónoma del País Vasco (BOPV, n 112).

5 Ley 4/2014, de 22 de diciembre, del Paisaje. Boletín Oficial de Cantabria (BOC) extraordinario, 29 de diciembre de 2014, $\mathrm{n}^{\circ}$ 67. Apenas anunciada la elaboración de la Ley, suscitó la "preocupación" de los municipios por la afectación que pudiera tener sobre el desarrollo de los nuevos Planes Generales de Ordenación Urbana. "Los municipios, "preocupados" por la "incidencia" de la futura Ley de Paisaje en los Planes Generales", El Diario Montañés, 24/12/2012. 
tos de ordenación, los "Planes Especiales", las "Directrices" y los "Estudios del Paisaje", entendidos como piezas básicas con vínculos directos con otros instrumentos de planificación espacial. Las "Directrices" tienen un carácter estratégico y se conciben de forma que puedan ser desarrolladas por los ulteriores instrumentos de planificación a los que vinculan. Las "Directrices" y los "Estudios del Paisaje" deberán ser aprobados mediante Decreto del Consejo de Gobierno en tanto que los "Proyectos de Actuación Paisajística" tendrán que ser sancionados por resolución de la Consejería o por el Ayuntamiento que los promueva. Se podrá exigir la realización del "Análisis de Impacto e Integración Paisajística” para las obras, construcciones o instalaciones en suelo rústico mientras que no serán preceptivos en los planes o proyectos de desarrollo de suelo urbano o urbanizable, salvo que así lo prevea el planeamiento.

En el anteproyecto de decreto por el que se aprobarían las "Directrices de Paisaje de Cantabria", presentado a los ayuntamientos en marzo de 2015, se propone el "Mantenimiento del paisaje agrícola tradicional y característico de los espacios rurales por su contribución a la variedad del paisaje e integración en él de las áreas urbanizables previstas" en referencia a los nuevos desarrollos urbanos ${ }^{6}$.

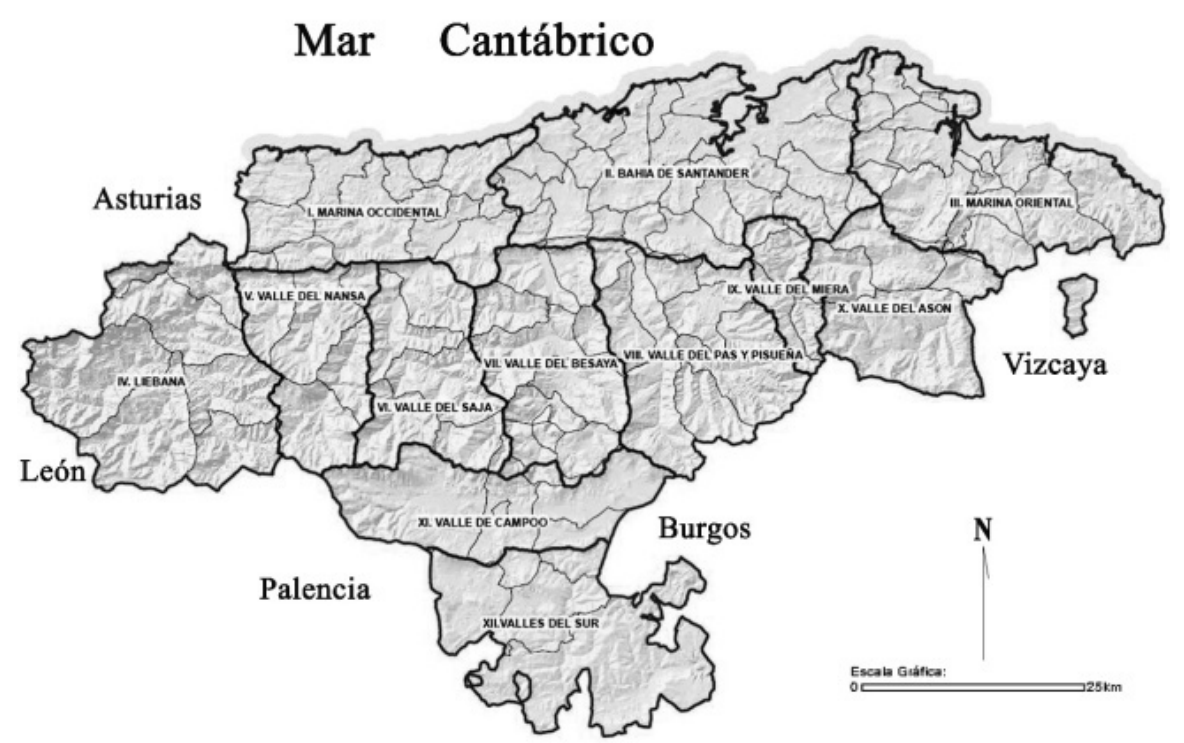

Fuente: elaboración propia a partir del mapa contenido en la Ley de Cantabria del Paisaje. Dirección General de Ordenación del Territorio del Gobierno de Cantabria.

6 La organización Ecologistas en Acción solicitó de inmediato "el aplazamiento del anteproyecto de decreto de directrices del paisaje en Cantabria por razones de economía y prioridad legislativa y hasta la adopción de una estrategia global e interdisciplinar de prevención de impactos sobre el paisaje”. El Eco Regional, 10/04/2015. 
En términos generales, la Ley se caracteriza por su imprecisión y ausencia de instrumentos normativos, si bien el Gobierno de Cantabria quedaba obligado por la propia Ley a fijar el calendario para la elaboración y aprobación de los instrumentos de ordenación así como del Catálogo de Paisajes Relevantes en el plazo de seis meses a contar desde la publicación de la Ley ${ }^{7}$.

Hasta la aprobación de la Ley del Paisaje que, como es natural, aún no ha tenido aplicación propiamente dicha, las únicas referencias a los paisajes rurales se encuentran dispersas en el resto de la legislación y normativa con incidencia territorial. Así, la Ley de Cantabria 11/1998, de 13 de octubre, de Patrimonio Cultural de Cantabria otorga consideración preferente a los paisajes culturales por su interés etnográfico, como exponentes de la relación establecida a lo largo del tiempo entre la comunidad humana y el medio natural y, particularmente, a los paisajes agrarios de estructura en mosaico de parcelas cercadas de muros y setos: mieses, erías y llosas $^{8}$, prados cerrados con cercas individuales que forman el mosaico parcelario, prados procedentes de la transformación de antiguos espacios de monte comunal y antiguas rozas en forma de recintos alveolares en áreas forestales, seles y otros pastos de montaña y fincas de prados cerrados con cabañas, altas cercas, ocasionalmente torreadas, de las antiguas citreras y viñedos y solares de aldeas y barrios de poblamiento tradicional. No obstante, pese a esta significativa, y relativamente temprana, concepción patrimonial del espacio y el paisaje agrario, en el inventario anexo no figura ni un solo paisaje rural o agrario salvo, únicamente, algunos núcleos rurales tradicionales calificados como "conjuntos históricos".

Por lo que se refiere a la normativa orientada a la regulación de los usos del suelo, la Ley de Cantabria 9/1994, de 29 de septiembre, de Usos del Suelo en el Medio Rural identificaba el suelo rural con "Suelo no Urbanizable" en razón de su excepcional valor agrícola, forestal o ganadero, de las posibilidades de explotación de sus recursos naturales y de sus valores paisajísticos. En consecuencia, entre las categorías del suelo no urbanizable figura la de "Suelo no urbanizable de interés agrario o paisajístico", compuesto por aquellos terrenos que requieren especial protección en función de dichas singularidades. En el mismo caso se encuentran los núcleos rurales que son "soporte de ocupación residencial tradicional” ( $\operatorname{art}^{\circ}$. 2.f.).

A comienzos del siglo actual se promulgó la Ley de Cantabria 2/2001, de 25 de junio, de Ordenación Territorial y Régimen Urbanístico del Suelo de Cantabria en la que se establece una serie de normas y estándares urbanísticos, de aplicación directa en el planeamiento municipal, referidos a la protección del paisaje ( $\operatorname{art}^{\mathrm{o}} .34$ de la Sección 2), con un enfoque estrictamente visual. Esta normativa dedica particular atención a la protección del suelo rústico subdividido en dos categorías: "de especial protección” y de "protección ordinaria", preservados ambos "de las construcciones propias de las zonas urbanas y de su desarrollo urbano integral” (art". 109.1). En su caso, el "suelo rústico de especial protección” quedaba sometido a un régimen incompatible con su transformación urbana "en razón de sus valores

7 Transcurridos dos años desde la aprobación, a fecha de diciembre de 2016 aún no se han publicado las Directrices ni el Catálogo.

8 Con estos vocablos se denominan en Cantabria, desde hace siglos, los tradicionales terrazgos de aldea de organización colectiva. Solían estar rodeados de una cerca común de piedra o de seto vivo que contenía en su interior un número variable de parcelas de propiedad privada y uso parcialmente privativo de los vecinos, generalmente abiertas y dedicadas a diferentes tipos de cultivos (cereales y viñedo principalmente). 
paisajísticos". Igualmente, la Ley preveía la posibilidad de que la Comunidad Autónoma formulase y aprobase "Planes Especiales" con la finalidad de la "Protección del paisaje, la riqueza etnográfica, los recursos naturales y el medio rural" (art". 59.1.g.).

La Ley del Suelo de Cantabria ha sido modificada recientemente en varias ocasiones. El primer ajuste importante se hizo a través de la Ley de Cantabria 2/2009, de 3 de julio, de Modificación de la Ley de Cantabria 2/2001 de Ordenación Territorial y Régimen Urbanístico del Suelo de Cantabria, con la finalidad expresada en el preámbulo de adecuarla "a las exigencias del tiempo actual" y un amplio repertorio de objetivos: eliminar las limitaciones a las actuaciones en suelo rústico, allanar la clasificación de nuevos suelos urbanizables y facilitar la rehabilitación de viviendas unifamiliares e instalaciones vinculadas a ocio y turismo rural en "suelo rústico de especial protección" con la condición de que esas obras se adapten al paisaje rural, lo que implica la exigencia de elaborar un proyecto de integración paisajística.

Más explícitas son las referencias al paisaje contenidas en la modificación realizada mediante la Ley de Cantabria 6/2010, de 30 de julio, de Medidas Urgentes en Materia de Ordenación del Territorio y Urbanismo, que representa una verdadera adulteración de algunos de los aspectos más novedosos y mejor valorados de la primigenia Ley 2/2001 a través de una consideración del paisaje que, cuando menos, se puede calificar de relativista. Expresamente, el texto de la Ley señala entre sus objetivos "la modificación de la norma-

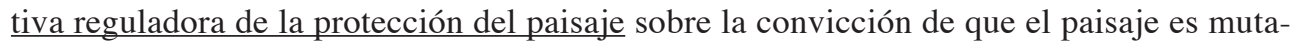
ble, experimenta constantes cambios que determinan que, lo que en un primer momento suponía un menoscabo de los valores paisajísticos por su inadecuación al entorno, posteriormente puede no ser sino una edificación más en un contexto ya transformado" ". De ahí que, entre las medidas adoptadas, se establezca la posibilidad de que los ayuntamientos promuevan la modificación del planeamiento para adecuarlo a la "nueva realidad física" de un paisaje transformado o degradado y de que se interrumpan los procesos de demolición cuando los propietarios de los edificios no integrados en el paisaje y el entorno acrediten fehacientemente la degradación del paisaje en el ámbito en que se encuentran por la presencia "de otras construcciones e instalaciones legalmente construidas con posterioridad" (art ${ }^{\circ}$. 5. Cuatro).

Dos años más tarde se ha promulgado la Ley de Cantabria 3/2012, de 21 de junio, de Modificación de la Ley de Cantabria 2/2001, de Ordenación Territorial y Régimen Urbanístico del Suelo de Cantabria (LOT. 3/12) a fin de "conceder al suelo rústico una serie de usos que permitan su puesta en valor y hagan posible darle un destino que coadyuve tanto a un desarrollo sostenible, como a la dinamización de los núcleos rurales tan necesaria en un contexto de crisis". Para ello se pretende facilitar "de forma inmediata la construcción en suelo rústico de vivienda unifamiliar aislada, así como de instalaciones vinculadas a actividades artesanales, culturales, de ocio y turismo rural" en los entornos de "Suelo Rústico de Protección Ordinaria" situados a menos de $200 \mathrm{~m}$ de los suelos clasificados como urbanos; en ellos se permite la edificación de vivienda unifamiliar aislada en parcelas de más de $2.000 \mathrm{~m}^{2}$.

9 De manera complementaria, se señala el objetivo de evitar comportamientos "antieconómicos como es la desaparición de edificaciones que en un primer momento eran paisajísticamente inarmónicas pero que, por circunstancias sobrevenidas motivadas por cambios en el entorno, no son ya disonantes". 
Poco después se introdujo otra modificación legal, la Ley de Cantabria 5/2012, de 11 de diciembre, de Reforma del Régimen Transitorio en Materia de Ordenación del Territorio y Urbanismo (LOT.5/12), que permite la práctica equiparación del "Suelo Rústico de Protección Ordinaria" con los suelos urbanizables ${ }^{10}$.

En 2013 se ha aprobado otra modificación de la Ley 2/200111 cuyos objetivos son: la "Adecuación del contenido de los instrumentos de ordenación del territorio regulados en la Ley a la nueva realidad social y económica surgida en un contexto muy distinto al del año 2001; [ ...] establecer pautas más flexibles que disciplinen el contenido de los distintos instrumentos de planeamiento urbanístico" (Propuesta de reforma de la Ley del Suelo de Cantabria, B) y agilizar los procedimientos de aprobación de instrumentos de planeamiento urbanístico, en sus distintos niveles y clases.

\section{LOS PAISAJES RURALES EN LOS INSTRUMENTOS DE PROTECCIÓN, ORDENACIÓN Y GESTIÓN AMBIENTAL}

La Ley de Cantabria 4/2006, de 19 de mayo, de Conservación de la Naturaleza de Cantabria, contempla como una categoría jurídica los "Paisajes Protegidos" en referencia a "aquellos lugares concretos del medio natural que, por sus valores estéticos y culturales, sean merecedores de una protección especial" ( $\operatorname{art}^{\circ} .13$ ). No obstante, aunque su función específica sea otra, entre los objetivos de la protección de los espacios naturales menciona el de "Conservar un paisaje rural de significativo valor cultural, histórico, arqueológico o paleontológico" (art ${ }^{\circ}$. 6.d.).

Por otra parte, una de las figuras de protección más representativa es la de "Parque Natural", que está concebida para valorar los ámbitos territoriales humanizados donde la agricultura tiene un peso considerable; en consecuencia, la gestión ambiental debe completar la salvaguarda de los recursos naturales con el mantenimiento de explotaciones agrarias viables como estrategia de lucha frente al abandono de tierras, la degradación ambiental y el deterioro de los paisajes (Mulero Mendigorri, 2013; Sánchez del Árbol, 2015).

Asimismo, el Plan de Ordenación de los Recursos Naturales (PORN) del Parque Nacional de Picos de Europa (R. D. 640/1994, de 8 de abril, BOE, n 113, de 12 de mayo de 1994) resalta que "el desarrollo ordenado de las actividades tradicionales es un objetivo prioritario para conseguir una conservación dinámica de dicho paisaje y el mantenimiento de la población” (art ${ }^{\circ}$. 7.1.A. Objetivos).

Por el contrario, el PORN del Parque Natural de las Marismas de Santoña, Victoria y Joyel (Decreto 34/1997, de 15 mayo) apenas hace referencia a la preservación, protección o, al menos, regulación de la actividad agraria y sus paisajes resultantes, aunque explicita que "la biodiversidad y el valor paisajístico que encierran -en particular allí donde se alternan setos, muros de piedra, mieses, senderos y caminos rurales- [...] uno de los

10 Para la aplicación eficaz de las Directrices de Paisaje, en proceso de elaboración, la organización Ecologistas en Acción estima imprescindible la derogación de la Ley 3/2012 "por contribuir a la generalización de impactos negativos sobre el paisaje en áreas de gran fragilidad, invadir vegas, mieses y laderas de suave pendiente con importantes valores agroecológicos y escénicos”. El Eco Regional, 10 de abril de 2015.

11 Ley de Cantabria 4/2013, de 20 de junio, relativa al régimen jurídico de las autorizaciones provisionales de edificaciones o actuaciones preexistentes, así como de adopción de distintas medidas para la agilización de los instrumentos de planeamiento. 
más frágiles y amenazados, por lo que su protección a largo plazo debe ser una prioridad" ( $\operatorname{art}^{\circ}$. 11.1.) y considera estos espacios como "Unidades Ambientales Secundarias".

En el caso del Parque Natural de los Collados del Alto Asón, su PORN (Decreto 2/2004, de 15 de enero) reconoce que "Los núcleos de población de reducido tamaño y el poblamiento disperso en cabañas favorecen la configuración de un paisaje de tipo bocage, de manera que los propios asentamientos constituyen un gran valor estético" ( $\operatorname{art}^{\circ}$. 8.5.2.). Establece, además, unas "Normas y directrices relativas a la protección y conservación del paisaje" que tendrán como objetivo "preservar el paisaje como un recurso más" ( $\operatorname{art}^{\circ}$. 10.2.5.). El mismo sentido tiene el estímulo de medidas destinadas al fomento de la explotación agropecuaria innovadora y respetuosa con el medio, en particular "la ganadería en régimen extensivo [...] mediante la creación y mejora de pastizales [...] y el uso de la agricultura de conservación o de mínimo laboreo" ( $\operatorname{art}^{\circ}$. 12.3.).

El Parque Natural Saja-Besaya, declarado en 1988, carece aún de PORN pero, en su defecto, el Plan Rector de Uso y Gestión (PRUG), aprobado por Decreto 91/2000, de 4 de diciembre, entre las siete zonas en que clasifica el ámbito del Parque, establece una "Zona Privada de Uso Agropecuario" formada por pequeñas fincas enclavadas en montes de Utilidad Pública, y en algunos casos con edificaciones de uso ganadero (invernales) o casas de recreo; en dicha zona se incluye el área o mies próxima a Bárcena Mayor destinada a praderas productivas y cultivo agrícola en la que se permiten las actividades agrícolas y ganaderas tradicionales.

El último PORN aprobado en Cantabria es el del Parque Natural de Oyambre, (Decreto 89/2010, 16 de diciembre de 2010). En la declaración del parque, en octubre de 1988, ya se consideraba entre las motivaciones culturales el hecho de que "Los paisajes del área constituyen uno de los ejemplos más representativos, hermosos, variados y mejor conservados del litoral cantábrico". El PORN fija una "Zona periférica de protección agrícola-ganadera" resultado de la secular actividad humana, especialmente la ganadera, que ha generado el paisaje más característico y singular del litoral cantábrico conformando un conjunto de notable valor ecológico, científico y paisajístico en un territorio antropizado.

En consecuencia, el PORN establece regulaciones específicas para la protección del paisaje a fin de potenciar "las acciones que aumenten la diversidad estructural y paisajística de las zonas con explotaciones agropecuarias, favoreciendo el mantenimiento y restauración de los sistemas de setos vivos con especies autóctonas y de cierres de piedra entre parcelas" (art". 44.4.).

\section{LOS PAISAJES RURALES EN LOS INSTRUMENTOS DE PLANIFICACIÓN TERRITORIAL}

De la Ley del Suelo de Cantabria 2/2001 emana el primer plan territorial cántabro contenido en la Ley de Cantabria 2/2004, de 27 de septiembre, del Plan de Ordenación del Litoral (POL), que establece los criterios generales de protección del medio y el paisaje litoral y de ordenación de usos y actividades en dicho área (Delgado Viñas, 2010 y 2015).

Desde la perspectiva de protección y gestión de los paisajes rurales, el POL diferencia un "Área de Protección de Interés Paisajístico", en la que sólo pueden autorizarse obras de rehabilitación de edificaciones preexistentes e instalaciones necesarias para las explotaciones agropecuarias, y un "Área de Ordenación de Modelo Tradicional”, que "se corresponde con los espacios agrarios de organización tradicional constituidos, por una parte, por los terrazgos de aldea, las mieses, y los diversos elementos delimitadores de las mismas, vegetales o inertes, y, 
por otra, por los terrazgos de monte, dedicados a pradería y labrantío, de significado valor agrario y ambiental" ( $\operatorname{art}^{\mathrm{o}}$. 9.1.b.). En relación con la gestión de estos espacios y paisajes agropecuarios, se dispone que en los núcleos tradicionales de menos de 40 viviendas, el planeamiento urbanístico podrá optar por crecimientos con vivienda unifamiliar aislada en suelo rústico que deberán proyectarse en las mieses contiguas al núcleo más alteradas, si bien la delimitación de la zona de crecimiento dentro de la mies no podrá superar la superficie del núcleo preexistente.

Dos años después se promulgaron las Normas Urbanísticas Regionales (NUR, Decreto 57/2006, de 25 de mayo, aprobadas de forma definitiva por Decreto 65/2010 el 30 de septiembre de 2010), que establecen criterios y fijan las pautas normativas del uso del suelo y la edificación para "salvaguarda de los valores del territorio, ya sean éstos medioambientales, paisajísticos, económicos o culturales”, en ausencia de planeamiento urbanístico municipal.

Las NUR contienen un elevado número de referencias al paisaje rural, en especial a los espacios rurales periurbanos en los que se afirma que se está produciendo "un borrado sistemático de las huellas, tanto construidas como naturales, del paisaje rural sobre el que se superpone la urbanización" (Memoria, p. 162), lo que se traduce en un notable deterioro paisajístico que exige urgentes actuaciones de protección. A partir de la clasificación del "Suelo Rústico" establecida en la Ley del Suelo de 2001, las NUR diferencian varias categorías de "Suelo Rústico de Especial Protección", entre otras las de:

- "Suelo Rústico de Especial Protección Paisajística": "las unidades territoriales de montes; de mieses en campos abiertos, en campos cerrados y en bancales; y las de terrazgos de monte en cierros y en abertales con valores paisajísticos preeminentes" ( $\operatorname{art}^{\mathrm{o}}$. 22.2.b.).

- "Suelo Rústico de Especial Protección del Patrimonio Territorial": las unidades territoriales de mieses y terrazgo de monte que reflejen las estructuras de la construcción social del territorio.

- "Suelo Rústico de Especial Protección Agropecuaria": las unidades territoriales de mieses y terrazgos cuyos valores agrarios tengan preeminencia sobre el resto por ser potencialmente productivos.

Por el contrario, el Plan Especial de la Red de Sendas y Caminos del Litoral (Decreto 51/2010, de 26 de agosto) no hace referencia ni a los paisajes rurales ni a los agrarios, en todo caso sólo a los forestales, y se fija especialmente en los paisajes naturales con un enfoque escénico y visual.

El Plan Especial de la Actuación Integral Estratégica de Reordenación de la Bahía de Santander (PEB), aprobado a través del Decreto 32/2015, de 14 de mayo (BOC de 11 de junio de 2015, $\mathrm{n}^{\circ}$ extraordinario 42), se plantea como finalidad "Compatibilizar el desarrollo urbanístico y la preservación de los valores ambientales, patrimoniales y paisajísticos [... así como] potenciar la identidad territorial de la Bahía, a partir de los elementos más representativos del territorio, el paisaje o el patrimonio construido" ( $\operatorname{art}^{\circ}$. 2.1.2.b.). Para cumplir tales objetivos establece, desde una perspectiva naturalista y visual, un "Área de Conservación Paisajística" que incorpora los «ámbitos que por su sobresaliente relevancia paisajística y alta exposición visual permiten la implantación de espacios libres, usos recreativos, deportivos, culturales, etc., como fórmula de potenciar su valor como miradores y lugares de disfrute y comprensión de los paisajes de la Bahía» ( $\operatorname{art}^{\circ}$. 7.1.d.). 
El criterio para establecer los grados de intervención en los “Ámbitos de Interés Territorial y Paisajístico (ITP)” consiste, esencialmente, en el nivel de exposición visual y de transformación urbanística preexistente ${ }^{12}$. En este aspecto, resulta especialmente significativa la única referencia expresa a las mieses, clasificadas como "Unidades Territoriales Culturales y Terrazgos Tradicionales", junto a los terrazgos de monte, al afirmar que "Las sucesivas transformaciones sufridas por el espacio de la Bahía hacen difícil reconocer de forma estricta los rasgos estructurales propios de estas unidades culturales de carácter territorial." (Estudios Territoriales, Documento de Información, p. 54) ${ }^{13}$.

Hasta el momento, el documento que dedica mayor atención a los paisajes rurales es el Plan Especial de Protección y Ordenación del Territorio Pasiego (PEPOTP), aprobado inicialmente el 26 de febrero de 2010, pero sin recorrido ni avances posteriores hasta el momento, cuyo objetivo explícito es la protección del patrimonio territorial y del paisaje pasiego frente a la demanda creciente de segunda residencia y las "tensiones inmobiliarias" en los municipios más próximos al área urbana de la bahía de Santander, la preservación de la calidad paisajística del territorio, así como el desarrollo y la dinamización socioeconómica del medio rural.

El PEPOTP parte de una concepción dual del paisaje, natural y cultural, superada hace tiempo, ("Proteger los paisajes naturales e intervenidos más valiosos y vulnerables" (Memoria I:18) y es el documento de planeamiento con más menciones al paisaje (203), aunque, paradójicamente, sólo contenga dos referencias explícitas al paisaje rural y ninguna al paisaje agrario. Distingue 12 tipos de paisaje (divididos en 42 unidades de paisaje) que quedan definidos mucho más por los elementos estructurantes naturales que por las intervenciones humanas, aunque se afirme de manera reiterada que "el paisaje pasiego es fruto de la dinámica secular de la actividad agropecuaria [...] un modelo de organización territorial basado en la explotación ganadera que ha conformado un paisaje único [...] construido por el hombre" (Memoria I: 144).

El modelo territorial queda formulado a partir de dos áreas básicas:

- Un “Área de Protección: de Cabañales, Ecológica y Paisajística” (ámbitos del territorio que por sus caracteres geomorfológicos, representatividad del modelo de vida pasiego ligado a la actividad agraria y excepcionales cualidades como fondo escénico, tienen un valor sobresaliente y característico del paisaje pasiego)

- Un "Área de Ordenación: Periférica de Transición" (con posibilidad de planificar desarrollos urbanísticos), de "Ordenación Agropecuaria" (espacios tradicionalmente dedicados a la actividad agraria en los que se consideran compatibles cambios de uso y nuevas edificaciones en suelo rústico) y de "Ordenación Forestal".

12 La población de la denominada "área metropolitana" de Santander, formada por 10 municipios además de la capital, ha experimentado un crecimiento de 238,2\% de 1900 a 2011, en particular desde los años sesenta del siglo XX. El Diario, 15 de mayo de 2015.

13 Inmediatamente después de su aprobación por el Gobierno de Cantabria, la Asociación para la Defensa de los Recursos Naturales de Cantabria, ARCA, ha alertado del "riesgo de perder el paisaje característico" del arco sur de la bahía de Santander al considerar que la zonificación es inadecuada y "contradice [...] el primer objetivo del Plan Especial de la Bahía que es el de mantener la calidad y unidad paisajística del ámbito del plan”. Europa Press, 15 de mayo de 2015 . 
Significativamente, se propone de forma expresa, aunque sin mayor concreción, el fomento de la actividad ganadera como agente de gestión y conservación del territorio: incentivar la adaptación del sistema de explotación ganadero tradicional a las nuevas demandas y necesidades sociales con el fin último de "salvaguardar ciertos paisajes rurales identitarios del territorio" (Memoria I: 174).

\section{LOS PAISAJES RURALES EN LOS INSTRUMENTOS DE PLANEAMIENTO URBANÍSTICO MUNICIPAL}

El retraso en la elaboración y actualización de los planes urbanísticos municipales ha sido una de las principales carencias de que ha adolecido la planificación espacial de Cantabria. En 2001, cuando se promulgó la Ley del Suelo de Cantabria, no contaban con Plan General de Ordenación Urbana (PGOU) nada más que 13 municipios de los 102 términos de la Comunidad Autónoma (12,7\%), otros 63 tenían aprobadas Normas Subsidiarias de Planeamiento (NNSS) y 20 habían elaborado Proyectos de Delimitación del Suelo Urbano (PDSU); únicamente 6 términos municipales, todos ellos de muy reducidas dimensiones poblacionales, carecían de cualquier instrumento de planeamiento (Delgado Viñas, 2010 y 2014b).

Este estado de cosas ha cambiado algo desde entonces, aunque la citada Ley daba un plazo de cuatro años para la adaptación de los planeamientos anteriores. A pesar de los avances recientes, a fecha de noviembre de 2016 y según la información publicada por la Dirección General de Urbanismo del Gobierno de Cantabria, tan sólo 32 municipios disponen de PGOU, 23 de los cuales tienen planes adaptados a la Ley 2/2001. 45 municipios tienen NNSS (sólo una de ellas posteriores al año 2001), otros 23 se rigen por DSU y DGSU (6 de ellos adaptados, total o parcialmente, a la Ley 2/2001) y 2 carecen de cualquier instrumento de planeamiento. En resumen, de los 102 términos municipales en que se organiza administrativamente la Comunidad Autónoma, únicamente 30 (29,4\%) disponen de instrumentos de planeamiento elaborados total o parcialmente en el siglo actual y acordes con la Ley cántabra del Suelo en vigor.

La primacía que todavía tienen en los municipios rurales los instrumentos de planeamiento de menor nivel (NNSS, DGSU y DSU) pone de manifiesto la fragilidad y el riesgo de los paisajes rurales y, en particular, de los paisajes agrarios, ya que este tipo de figuras otorgan escasa atención al suelo no urbanizable puesto que los valores medioambientales, productivos y paisajísticos del suelo rústico no están explicitados ni, por ende, quedan protegidos y gestionados con la eficacia deseable.

En razón de lo anterior, para hacer el estudio del tratamiento de los paisajes rurales y agrarios en el planeamiento municipal se han seleccionado únicamente los municipios rurales que disponen de PGOU adaptado a la Ley del Suelo de 2001, aún vigente aunque muy reformada. Son 22 Planes (descontado el PGOU de la capital, Santander, que, además, acaba de ser anulado por el Tribunal Supremo), que constituyen un repertorio amplio y variado, lo que, a mi entender, proporciona suficiente representatividad y fiabilidad a las conclusiones que se puedan extraer de su análisis. Cabe añadir, además, que, entre los 22 municipios considerados, existen numerosos casos de espacios litorales, tanto de la Marina occidental como de la oriental, de términos ubicados en los valles medios y en áreas de montaña, de municipios de considerables dimensiones poblacionales y de otros minúsculos, así como de espacios rurales profundos y de otros periurbanos y semiurbanos, etc. 


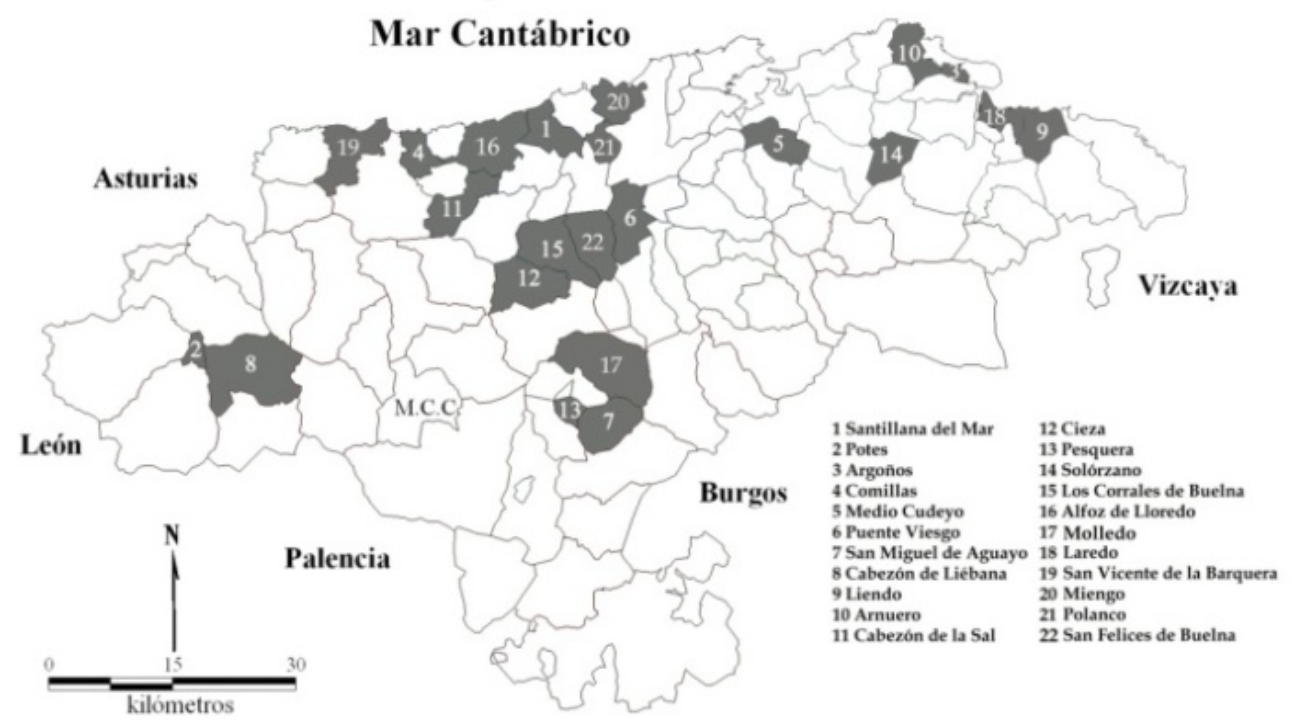

Fuente: elaboración propia.

La identificación numérica de los municipios corresponde a la fecha de aprobación de sus respectivos PGOU en sentido ascendente.

Además del análisis pormenorizado de todos y cada uno de los planes, se han utilizado como indicadores significativos la localización y situación de cada término en el contexto regional y sus dinámicas poblacional e inmobiliaria recientes, al considerar que estos datos contribuyen a contextualizar y, en cierta medida, a explicar los rasgos esenciales y los objetivos, explícitos e implícitos, de sus respectivos instrumentos de ordenación municipal.

\section{V.1. Los PGOU con escasa valoración del paisaje agrario}

\section{V.1.1. Potes}

Entre los de este tipo cabe resaltar el PGOU del pequeño municipio de Potes $^{14}$ (BOC, 9 de mayo de 2005, $\mathrm{n}^{\circ}$ 87), que funciona como núcleo central y capital de la comarca de Liébana, situada en el extremo más occidental de Cantabria en su límite con Asturias, un territorio que ya en 1968 fue declarado "Paisaje Pintoresco".

En la Memoria de su PGOU se expone, como declaración de intenciones, que "La planificación territorial no puede ignorar el paisaje como elemento tan determinante como aquellos otros que tradicionalmente sí han sido observados". No obstante, en el resto del documento

14 Ubicado en el borde del macizo de los Picos de Europa, el término municipal se extiende por una superficie de $7,7 \mathrm{~km}^{2}$ en los que viven 1.413 habitantes en 2015 . 
apenas vuelve a hacerse referencia al paisaje nada más que de forma declaratoria e imprecisa y advirtiendo expresamente que, aunque uno de los objetivos es que "se mantenga el alto nivel paisajístico [...] ello tampoco significa que el desarrollo social y económico de Potes deba subyugarse total y absolutamente en aras a un "status quo" paisajístico" (Memoria: 82).

Tales declaraciones, por otra parte, apenas tienen traslación a la práctica ordenadora y normativa ya que, a la hora de calificar el "Suelo Rústico de Especial Protección Agrícola y Ganadero", se distinguen nominalmente las categorías de "Prados", "Viñedos" y "Frutales", atendiendo exclusivamente al tipo de cultivos, sin una sola referencia a los paisajes agrarios y teniendo como único motivo de preocupación la percepción visual del "paisaje arquitectónico y natural" del municipio.

\section{V.1.2. Cabezón de Liébana}

Más llamativo aún resulta el tratamiento del paisaje agrario o, mejor aún, la carencia de su consideración, en el PGOU de Cabezón de Liébana (BOC, 28 de Agosto de 2013, nº 38 extraordinario), un municipio contiguo al anterior y plenamente rural ${ }^{15}$, entre otros motivos por tratarse de uno de los planes más recientes, elaborado en un contexto de ausencia de presión inmobiliaria y coetáneo de la elaboración de la Ley del Paisaje de Cantabria.

Pese a que se hace referencia a la Ley 11/1998 de Patrimonio Cultural de Cantabria, no se refieren nunca los apartados de la norma que conciernen a los paisajes agrarios, por lo que dicha mención debe ser considerada como una alusión banal, sin más función que la de cumplir un requisito. Por el contrario, y en coherencia con lo anterior, queda bien explicitado que la finalidad del PGOU es brindar "a Cabezón de Liébana una oportunidad para impulsar su desarrollo económico a la que no debe ser ajeno el planeamiento urbanístico" a partir de la identificación exclusiva del desarrollo económico con el desarrollo turístico (Memoria:126) ${ }^{16}$.

El principal impedimento que el Plan erige para la preservación de los paisajes agrarios reside en la clasificación como "Suelo Rústico de Protección Ordinaria", fácilmente edificable desde 2012, de una amplia superficie clasificada anteriormente como "Suelo Rústico de Especial Protección”. Por el contrario, en la categoría de "Suelo Rústico de Especial Protec-

15 Hasta esta fecha el municipio se regía por una Delimitación de Suelo Urbano aprobada en mayo de 2004; la justificación de la elaboración del PGOU parece estar relacionada con el aprovechamiento de las ventajas aportadas por la modificación de la Ley del Suelo de 2001 mediante la Ley 3/2012 que "junto a factores como la aparición de nuevos procesos urbanísticos, los cambios en los hábitos sociales y otros fenómenos menores como el prometedor desarrollo del turismo rural, parecen exigir un cambio en la planificación municipal capaz de reorientar el modelo (de forma integral) para adecuarlo a la nueva realidad" (Memoria:131).

16 El instrumento que propone el PGOU para impulsar ese tipo de crecimiento es el estímulo de la función residencial secundaria como objetivo prioritario a través de la ampliación del suelo urbano y urbanizable en más de un $30 \%$ puesto que, según los redactores del Plan, "Este incremento responde [...] a satisfacer las necesidades de un territorio que tiene el espacio urbano prácticamente agotado" (Memoria:134). En realidad, la demanda de viviendas principales debe ser muy reducidas si se tiene en cuenta que la población residente en el término municipal había sufrido una merma de -20,5\% entre 1996 y 2015 pasando de 782 a 622 habitantes en las respectivas fecha, pese a lo cual se calcula que en los 8 años de vigencia del Plan la población prevista sería de 1.419 habitantes. Según el Censo de Viviendas de 2011, sólo 151 viviendas, de un total de 531 (28,4\%), podían considerarse secundarias o vacías. Tampoco parece plausible la hipótesis de crecimiento poblacional a partir de la descongestión de Potes, la vecina capital comarcal, que también ha perdido población en el mismo plazo de tiempo $(-12,9 \%)$. 
ción Paisajística" sólo se incluyen los que "se corresponden con el típico paisaje de la montaña media cantábrica" (ibidem:141); se trata, en general, de áreas de ladera con pendientes pronunciadas y ocupadas por monte bajo y arbolado, suelos descartables o menos atractivos para la construcción residencial, en consecuencia.

\section{V.1.3. Los Corrales de Buelna}

Los Corrales de Buelna, un municipio, situado en el valle medio del río Besaya, ha visto aprobado su PGOU también recientemente (BOC, 13 de febrero de 2015, nº extraordinario 9). Su capital tiene claras funciones semiurbanas como cabecera comarcal en el sector central del denominado "corredor del Besaya", que une la Marina Occidental y la culminación del tramo central de la Cordillera Cantábrica, por lo que posee una dinámica demográfica e inmobiliaria de notable crecimiento ${ }^{17}$. Tal vez esa circunstancia podría explicar que la protección del paisaje agrario y del suelo rústico no sean, en absoluto, un objetivo prioritario por lo que la clasificación predominante es, igualmente, la de "Suelo Rústico de Protección Ordinaria" (SRU-PO) para los terrenos que constituyen espacios más humanizados y/o de menor valor, incluyendo en éstos las vegas o mieses (Penías), en las que sólo queda prohibida la construcción de nuevas instalaciones productivas, salvo que tengan carácter artesanal o sean instalaciones de ocio y turismo rural, pero no la de viviendas unifamiliares aisladas en parcelas con más de $5.000 \mathrm{~m}^{2}$.

\section{V.1.4. Pesquera}

El PGOU de Pesquera (BOC, 26 de noviembre de 2014, $\mathrm{n}^{\circ}$ extraordinario 63) puede servir como prueba palpable de que la mayor o menor sensibilidad del planeamiento hacia los paisajes agrarios no siempre está relacionada con el tamaño poblacional e inmobiliario del término, con su dinámica socioeconómica o con su carácter más o menos rural, ni siquiera con su localización, emplazamiento o situación.

El pequeño municipio de Pesquera está situado algo más al sur en el mismo "corredor del Besaya", en el curso alto de este río cerca de la culminación de la cordillera, en la comarca de Campoo ${ }^{18}$. En su Plan no se reconoce valor paisajístico alguno a los espacios agrarios, ni siquiera se hace una identificación nominal de las mieses, salvo una imprecisa referencia a una "unidad paisajística de praderías y tierras de labor" (Memoria:81). No puede sorprender, por tanto, la definición, sin criterio explícito ni precisión, del "Suelo Rustico de Especial Protección Paisajística" en el que se incluyen "las unidades territoriales de monte, cierros y aberdales (parcelas de prado abiertas), cuyos valores paisajísticos sean tales que resulte interesante su preservación" (ibidem:331).

17 En 2015 la población municipal son 11.077 habitantes (7,7\% más que en 1996). El parque de viviendas ascendía en 2011 a 5.579, de las cuales 4.505 eran viviendas principales (80,7\%). De 2001 a 2011 el volumen total de viviendas había crecido en $27,8 \%$ y el de las viviendas principales en $22,8 \%$.

18 Se trata de un espacio profundamente rural con sólo 73 habitantes en 2015 ya que desde 1996 ha perdido el $31,1 \%$ de su población. De las 72 viviendas que tenía en 2011,44 (61\%) eran principales (en 2001 estaban censadas 84 viviendas). 


\section{V.1.5. Molledo}

Colindando con el anterior, el término municipal de Molledo ha obtenido la aprobación de su PGOU también en fechas recientes (BOC, 3 de julio de 2015, $\mathrm{n}^{\mathrm{o}}$ extraordinario 51). Aunque de mayores dimensiones poblacionales, las condiciones derivadas de su localización y sus dinámicas demográfica e inmobiliaria no ofrecen grandes diferencias ${ }^{19}$.

Asimismo, el paisaje rural, en general, y el agrario, en particular, consiguen exigua atención. Las unidades de paisaje se establecen a partir de criterios esencialmente orográficos (llanuras de fondo de valle, laderas, cimas, etc.) y como elementos antrópicos sólo son considerados los núcleos de población y las infraestructuras viarias, con omisión absoluta de los espacios de uso agropecuario, pese a afirmar que el «Suelo Rustico de Espacial Protección Agropecuaria» (REPA) corresponde a «un conjunto de espacios no urbanizados con un alto valor agrológico, paisajístico y medioambiental. Son espacios que transmiten la imagen tradicional de las zonas de cultivos y de los prados de siega que han configurado el paisaje de la región y que, en Molledo, cuentan con una singular presencia» (Memoria:99). Precisamente sobre una significativa parte de algunos de estos espacios se extienden las corolas colindantes con los núcleos, clasificadas en el Plan como "Suelo Rústico de Protección Ordinaria» con la intención de permitir la edificación y los usos residenciales y productivos según la Ley 3/2012.

\section{V.1.6. Laredo}

El municipio de Laredo no es enteramente rural, pero sí posee una notable parte de su superficie con espacios rurales y paisajes agrarios dignos de ser considerados. El núcleo principal, plenamente urbano, ha funcionado como una pequeña ciudad especializada precozmente en las actividades de ocio y esparcimiento, de veraneo desde finales del siglo XIX y plenamente turísticas desde mediados del siglo $\mathrm{XX}^{20}$.

A pesar de que entre los objetivos teóricos especificados en la Memoria de su PGOU (BOC, 6 de julio de 2015, no extraordinario 53 y 54) ${ }^{21}$ se explicita el de "Proteger de la des-

19 En 2015 el municipio cuenta con 1.595 personas como resultado de una continua pérdida de población que, desde 1996, se cifra en $-21,2 \%$ de sus habitantes. El parque de viviendas, que en 2011 constaba de 1.054 unidades (661 principales, 62,7\%) apenas ha crecido en los últimos años: en 2001 estaban censadas 1.011 viviendas con una distribución por tipos de uso muy similar: 676 principales $(66,8 \%), 194$ secundarias y 130 vacías. No obstante, en la Memoria del PGOU se afirma que entre 2001 y 2012 se habían concedido licencias de construcción para unas 110 nuevas viviendas que colmatarían la mayor parte del suelo urbano aún no desarrollado.

20 La población asciende a 11.643 habitantes en 2015 pese a haber sufrido significativas mermas en las últimas décadas (desde 1996 ha perdido 9,8\% de su población). El parque inmobiliario constaba en 2011 de 16.321 viviendas familiares de las cuales únicamente 4.705 eran viviendas principales $(28,8 \%), 10.688$ eran viviendas secundarias $(65,5 \%)$ y 928 viviendas vacías. Aunque su dinámica inmobiliaria ha sido mucho más moderada que la de otros términos litorales próximos durante la etapa de la "burbuja" (desde 2001 se habían construido 1.413 viviendas, 9,5\%), el PGOU plantea una capacidad máxima de 22.091 viviendas para 66.273 habitantes.

21 El PGOU de Laredo comenzó a elaborarse en el año 2000, se aprobó en mayo de 2015 y ha sido anulado a finales de 2016 por el Tribunal Superior de Justicia de Cantabria, con posterioridad al análisis realizado para su inclusión en este trabajo de investigación. Por sus especiales características y porque los motivos alegados para la anulación nada tienen que ver con los aspectos aquí tratados, se ha considerado conveniente seguir considerándolo en la versión definitiva de este artículo. 
aparición los paisajes rurales tradicionales que ofrecen una interesante fusión de naturaleza y cultura, pues constituyen un valioso patrimonio histórico, apenas apreciado” (Memoria: 99), al identificar las unidades de paisaje no hace referencia nada más que a praderas y bosques, lo que manifiesta un claro olvido del significado de los paisajes agrarios porque, desde un enfoque plenamente urbano, de lo que se trata "es de acercar a la población al disfrute del medio natural que rodea al casco urbano de Laredo, fomentando la relación directa con el paisaje y los valores del medio rural y parque natural" (ibidem:174).

\section{V.1.7. San Vicente de la Barquera}

Tampoco el PGOU de San Vicente de la Barquera (BOC, 18 de agosto de 2015, n $^{\circ}$ extraordinario 65) muestra especial sensibilidad en lo relativo al paisaje rural. El municipio barquereño está situado en la costa de la Marina occidental e incluido físicamente en el Parque Natural de Oyambre, lo que implica, al mismo tiempo, una gran especialización en las actividades de ocio y turísticas, una gran presión constructiva e importantes limitaciones urbanísticas $^{22}$.

El concepto de paisaje manifiesto en el Plan puede calificarse de confuso, ambiguo y sin conexión alguna con el contenido en el Convenio del Paisaje. Revela una concepción exclusivamente naturalista para la que la intervención humana parece ser un demérito al no llegar a entender el paisaje como una construcción social, a pesar de afirmar, vanamente, que "Desde el punto de vista etnológico el paisaje es consubstancial con las formas de vida social y observándolo se puede describir el tipo de sociedad que lo generó" (Memoria:107). Algunas mieses y otros terrazgos son clasificados como "Suelos de Especial Protección Agropecuaria" (R_EPA [sic]) únicamente por sus valores agronómicos en relación con «futuros planes de desarrollo agrario de la región» (ibidem) y no se establece la categoría de "Suelo Rústico de Especial Protección Paisajística”.

\section{V.1.8. Miengo y Polanco}

Miengo y Polanco son dos municipios de la franja periurbana comprendida entre las dos principales ciudades de la Comunidad Autónoma, Santander y Torrelavega, más próximos a esta última, en relación con la que funcionan desde hace tiempo como espacios de descongestión residencial, aunque con distinto significado ${ }^{23}$ : en Miengo la función residencial tiene un carácter mixto, casi al 50\%, de vivienda principal y de residencia secundaria;

22 Su población asciende a 4.247 habitantes en 2015 tras una leve pérdida reciente $(-3,4 \%$ desde 1996) atribuida generalmente a las restricciones para ampliar el parque de viviendas. No obstante, en 2011 éste constaba de 3.850 unidades, la mayor parte de las cuales eran viviendas secundarias y vacías $(56,2 \%)$, cifra a la que se había llegado a partir de la construcción de 843 nuevas viviendas desde 2001 (+28\%). Según los datos facilitados por el propio Ayuntamiento, en el período 2001-2014 se concedieron 998 licencias de primera ocupación, con especial intensidad entre 2005 y 2008.

23 En 2015 Miengo tiene 4.675 habitantes fruto de un importante crecimiento durante las dos últimas décadas (36\% desde 1996). En Polanco viven en la misma fecha 5.705 personas tras un incremento de 55,9\% en los últimos veinte años. El crecimiento del parque de viviendas de ambos municipios ha sido aún más espectacular. En el caso de Miengo el censo de 2011 arroja un volumen de viviendas superior en 89,9\% al de 2001; en el de Polanco el aumento del número de viviendas entre ambos censos es, incluso, mayor $(93,4 \%)$. 
en Polanco el predominio absoluto corresponde a la vivienda principal de uso permanente hasta llegar a funcionar prácticamente como un barrio periurbano de Torrelavega ${ }^{24}$.

Los objetivos de los respectivos PGOU, aprobados en fechas muy próximas entres sí, apuntalan estas funciones. Así, el PGOU de Miengo (BOC, 26 de noviembre de 2015, nº extraordinario 94) proyecta un horizonte de 4.884 viviendas para 12.802 habitantes y una población estacional en vivienda secundaria de 4.648 habitantes, con posibilidad de crecimiento hasta 6.381 personas. El PGOU de Polanco (BOC, 7 de abril de 2016, $\mathrm{n}^{\circ}$ extraordinario 11) plantea la capacidad de construcción de 1.611 nuevas viviendas para otros 4.833 habitantes, al mismo ritmo edificatorio de la primera década del siglo XXI, la de la burbuja inmobiliaria.

Frente a estos objetivos prioritarios, ninguno de los dos instrumentos de planeamiento hace apenas referencia al "Suelo Rústico de Especial Protección», más allá de una mínima mención, en el caso de Miengo, al sistema denominado de "praderas interiores", consideradas, sorprendentemente, como un espacio de valor protegido por ser "la base de la economía rural" (Memoria:90). El PGOU de Polanco se limita a señalar que el "Suelo de Especial Protección Paisajística y Forestal" es el clasificado en el POL.

\section{V.1.9. San Felices de Buelna}

No difiere mucho de los anteriores el último PGOU aprobado en 2016, el de San Felices de Buelna (BOC, 9 de mayo de 2016, $\mathrm{n}^{\circ}$ extraordinario 15), un término municipal situado entre Los Corrales de Buelna y Puente Viesgo ${ }^{25}$. El Plan no manifiesta preocupación alguna por la protección del paisaje rural ni del suelo rústico, salvo una leve alusión a la "zona de vega", en la que "el paisaje está caracterizado por el uso agropecuario del suelo y su organización en mieses" (Memoria Justificativa:22); casualmente, el suelo clasificado como urbanizable coincide, precisamente, con buena parte de esas mieses.

\section{V.1.10. Argoños}

En algunos aspectos, contrasta con los anteriores el PGOU (BOC, 16 de marzo de 2007, $\left.\mathrm{n}^{\circ} 54\right)$ de Argoños, un diminuto término municipal (5,51 $\left.\mathrm{km}^{2}\right)$ localizado en la Marina oriental que, desde finales de la década de los años ochenta ha adquirido notables funciones residenciales de segunda vivienda vinculadas con el área metropolitana de Bilbao ${ }^{26}$. En relación

24 En 2011 en Miengo había 4.125 viviendas de las que el 49\% eran no principales frente al 40,6\% en 2001. De las 2.928 viviendas censadas en Polanco en 2011 sólo 848 (28,9\%) eran no principales, si bien la mayor parte de ellas no son viviendas secundarias sino vacías, de muy reciente construcción y aún sin ocupar.

25 En 2015 habitan en el municipio de San Felices 2.408 personas y también ha tenido una evolución demográfica positiva (8\% desde 1996), similar a la dinámica inmobiliaria (censadas $11,7 \%$ viviendas más en 2011 que en 2001). De las 993 viviendas que tenía en 2011 sólo 28 (2,8\%) eran no principales. Según el PGOU, en 2015 había 1.071 viviendas de las cuales 207 vacías; para un horizonte de 10 años, el Plan prevé un máximo de 1.528 viviendas más para 4.447 habitantes ya que el municipio es considerado como un espacio de expansión residencial para residentes permanentes cuya ocupación laboral tendría lugar, preferentemente, en los términos colindantes de Torrelavega y Los Corrales de Buelna.

26 Argoños tiene 1.744 habitantes en 2015 y 1.275 viviendas en 2011 , de las que son viviendas principales únicamente 624 (48,9\%). Su población ha aumentado 124,2\% desde 1996 y el volumen de viviendas únicamente 
con lo cual han ido surgiendo desde entonces nuevos núcleos de urbanizaciones de viviendas unifamiliares, exentas, pareadas y adosadas, y algunos bloques de apartamentos en altura que han distorsionado el modelo tradicional de asentamientos, hasta el punto de que, según la propia memoria del PGOU, “los núcleos tradicionales desaparecen sumergidos en un mar de urbanizaciones de residencia secundaria sin personalidad ni carácter propio y sin vinculación con la trama preexistente ni con las relaciones productivas del territorio" (Memoria:12).

Tal proceso ha tenido lugar en una situación de vacío legal generado por la anulación de las Normas Subsidiarias y, parcialmente, del Plan de Ordenación de los Recursos Naturales del Parque Natural de las Marismas de Santoña, en el que se incluye buena parte del territorio municipal; circunstancias que se han visto complicadas por la existencia de unas 260 viviendas con sentencia firme de derribo en estos momentos, algunas de ellas precisamente por conflictos paisajísticos.

No debe sorprender, por tanto, que uno de los objetivos del PGOU sea la "integración paisajística de determinadas áreas urbanas" (ibidem:22) y que el documento ponga énfasis en la definición precisa de los criterios paisajísticos concretos que se deben proteger para evitar conflictos futuros. Para ello se incorpora por primera vez en Cantabria, al decir de la propia Memoria, normativa de protección del paisaje de acuerdo con las sentencias judiciales y los criterios paisajísticos de la Convención Europea del Paisaje (sic, p. 90 ss.). Pero, tal vez, ya era demasiado tarde cuando la mayor parte de los suelos de superior calidad agronómica habían dejado de ser utilizados para la actividad agraria, casi extinguida en el municipio, o prácticamente habían desaparecido enterrados bajo las nuevas urbanizaciones, por utilizar una expresión similar a la contenida en la Memoria del Plan. Si bien se integran en la categoría de "Suelo Rústico de Especial Protección Agropecuaria", tienen una valoración casi marginal como "espacios más humanizados y/o de menor valor, por lo que su protección puede ser compatible con el mantenimiento, fomento e incluso implantación de usos y formas de ocupación del territorio tradicionales de la zona" (Normativa:88). Por el contrario, en los de "Especial Protección Forestal" "los procesos de urbanización son incompatibles con el mantenimiento de la riqueza forestal" (ibidem).

Tal desigualdad parece ser fruto de una consideración ambientalista o naturalista del paisaje, al concebirlo esencialmente "como elemento del medio ambiente [...] aglutinador de una serie de características del medio físico" (Memoria:90), tomando como referencia explícita la clasificación dual del paisaje contenida en el Informe Dobris (1991) ${ }^{27}$. Aunque se entiende, en teoría, que todo el paisaje del término es cultural, "en el que se refleja la población, la economía, la sociedad y la cultura histórica del municipio y sus usos" (ibidem), paradójicamente, no se confiere ningún valor patrimonial a este tipo de paisaje.

en $6,2 \%$ desde 2001. En esta última fecha, de un total de 1.200 viviendas familiares, sólo 362 eran viviendas principales $(30,2 \%)$. Estos datos parecen indicar que muchas viviendas secundarias se han convertido en viviendas principales con la consiguiente conversión de sus habitantes temporales en residentes permanentes.

27 La valoración del paisaje subyacente en el documento se apoya en el criterio del grado de "naturalidad" y de la apreciación negativa de la intervención humana sobre el medio. Así, al referirse a algunos espacios se explicita que "se trata de un paisaje modificado y alterado por la actividad humana donde el grado de naturalidad ha desaparecido y por ello se proponen una serie de medidas que regeneren las condiciones del medio" (Memoria:92). En general, se concluye que se considerarán áreas de protección paisajística "todas aquellas que, por su destacada posición en el marco urbano o rural, constituyen perspectivas visuales de carácter singular” (ibidem:93). 


\section{V.1.11. San Miguel de Aguayo}

Similar concepción del paisaje, estrictamente naturalista, presenta el PGOU (BOC, 2 de mayo de 2013, $\mathrm{n}^{\mathrm{o}} 17$ extraordinario) de San Miguel de Aguayo, un municipio ubicado en el área de la cabecera del río Besaya, como alguno de los analizados antes, con una población de 164 habitantes, en 2015, dedicados esencialmente a la ganadería extensiva y a la explotación hidroeléctrica de los embalses de Alsa y Mediajo ${ }^{28}$.

Desde la perspectiva del tratamiento del paisaje, la memoria del PGOU hace una descripción somera de varias "cuencas de visibilidad", integradas en el análisis del "territorio y medio físico" y sin corresponder a conceptos ni criterios paisajísticos propiamente dichos. Entre ellas destacan la unidad de "Núcleo Rural", entendida como el espacio humanizado organizado en células de casa-huerto cercados (antuzanos o ariales [sic]), y la unidad de "Praderías y Pastizales", que corresponde a los terrazgos conocidos como mieses en otras comarcas y denominados aquí eras, formados por parcelas de cultivo reconvertidas en prados hace mucho tiempo.

En cualquier caso, en el texto se trasluce el claro predominio que se otorga a los elementos naturales del paisaje, identificado con un teórico medio natural preexistente a la acción humana, que interviene sobre él mediante "modificaciones antropogénicas realizadas sobre el paisaje" (Memoria:80); de ahí la consideración del factor naturalidad como un valor superior.

\section{V.1.12. Medio Cudeyo}

Pese a las enormes diferencias de localización, condiciones socioeconómicas y dinámica demográfica e inmobiliaria con el anterior, el PGOU del término municipal de Medio Cudeyo (BOC, 18 de febrero de 2011, $\mathrm{n}^{\circ} 34$ ) presenta grandes similitudes en cuanto al tratamiento que otorga al paisaje rural y agrario.

Este municipio está situado en el sector meridional del área periurbana de Santander y goza de un elevado nivel de accesibilidad desde la capital regional a través de las autovías que circunvalan la bahía de Santander y por ferrocarriles de vía estrecha, que funcionan como trenes de cercanías. Estas ventajas de situación explican el importante crecimiento de la población y del parque inmobiliario ${ }^{29}$ en las dos últimas décadas a partir de la atracción de habitantes de procedencia urbana y rural, ocupados de forma predominante en la industria y los servicios, en especial en los núcleos septentrionales, sobre todo en el de Solares. La

28 San Miguel de Aguayo constituye un caso sorprendente en el contexto de los municipios de montaña de Cantabria ya que, a diferencia de la mayor parte de ellos, su población no ha experimentado merma alguna en los últimos años, bien al contrario, desde 1996 a 2015 ha crecido 3,1\%. Un aumento que suele explicarse por el disfrute por parte de los vecinos de importantes beneficios económicos derivados de los ingresos municipales percibidos por la explotación de los embalses y por el empleo complementario que esta actividad proporciona. Una circunstancia que se refleja también en la evolución del parque de viviendas, prácticamente con el mismo volumen en 2001 y 2011 pero con una significativa diferencia, la proporción de viviendas principales pasa de 56,7\% en 2001 a $84,9 \%$ en 2011.

29 Su población ha pasado de 5.904 habitantes en 1996 a 7.530 en 2015 (27,5\%); el parque inmobiliario del municipio constaba de 2.516 viviendas en 2001 y de 3.333 en 2011 (32,47\%), la mayor parte de las cuales, 2.750, son viviendas principales y únicamente 159 son viviendas secundarias. 
actividad agropecuaria, por el contrario, se ha visto reducida a los núcleos de población más alejados del litoral y de los nudos de comunicación, al tiempo que ha menguado también la superficie dedicada a este aprovechamiento ante las expectativas generadas por el proceso urbanizador.

El nuevo PGOU se propone la definición de los elementos que caracterizan el suelo rústico de forma suficientemente objetiva, clara y concreta para que "puedan justificar las razones por las que se protege el suelo de la acción urbanizadora” (Memoria:84) y muestra un notable interés por el Suelo Rústico de Especial Protección. Asimismo, distingue con claridad cinco áreas singulares de suelo, para alguna de las cuales (la Ría de San Salvador) el argumento de su protección reside en el "carácter específico de marisma y praderas costeras [que] definen un ámbito específico de alto interés ambiental y paisajístico, que debe ser preservado en nivel de protección absoluta" (ibidem). Asombra por ello, en mayor medida, que no se haga ni una sola referencia al valor de los paisajes agrarios de estas áreas en las que se ordena la limitación de los desarrollos urbanísticos en función de la mayor calidad y fragilidad visual y en las que se imponen condiciones y tipologías de edificación que eviten o minimicen el impacto paisajístico.

\section{V.1.13. Puente Viesgo}

Puente Viesgo es un municipio que se encuentra a medio camino entre la Marina y la Montaña, compartiendo caracteres con ambos ámbitos espaciales. Está situado en el cruce de la vía de comunicación que, en sentido norte-sur, conecta el litoral central de Cantabria con la Meseta castellana y de la vía, transversal a ella, que une el País Vasco con Asturias. En este aspecto puede afirmarse que el área septentrional del municipio funciona como un nudo de comunicaciones en el que se entrelazan el eje de comunicación Santander-Burgos (N-623) y el eje Bilbao-Oviedo (N-634) en el llamado Cruce de Vargas. Esta situación ha favorecido un acelerado proceso de rururbanización en relación con las dos principales ciudades de Cantabria, Santander y Torrelavega, de las que la capital municipal dista 29 y 14 $\mathrm{km}$ respectivamente ${ }^{30}$.

Hasta la aprobación de su PGOU (BOC, 20 de agosto de 2012, nº 30 extraordinario) el municipio se rigió por unas NNSS aprobadas en 1998 en un contexto de gran disponibilidad de suelo urbanizable y notable actividad edificatoria, lo que hizo posible la construcción de un elevado número de viviendas en pocos años. La Memoria del Plan trasluce la preocupación por la degradación del paisaje tradicional como consecuencia de la reciente presión urbanizadora en los tres núcleos más accesibles: Vargas (donde el crecimiento del parque de viviendas ha sido espectacular en los últimos años), Puente Viesgo, la capital municipal, y Las Presillas; asimismo, el actual Plan se propone "procurar un crecimiento más ordenado, respetuoso con los valores ambientales y culturales y acorde con la capacidad de acogida del territorio" (Memoria:16).

30 En el municipio habitan 2.886 personas en 2015 y tenía 1.179 viviendas en 2011, principales la mayor parte de ellas (94,5\%; la proporción de viviendas principales en 2001 era 79\%). Su población ha crecido $25 \%$ desde 1996 y el parque de viviendas $29 \%$ de 2001 a 2011. 
Desde la perspectiva que nos ocupa, el Plan concede gran atención al paisaje, también con una concepción fundamentalmente naturalista y visual, por lo que no resulta sorprendente que el principal criterio de valoración paisajística sea, al igual que en algunos casos reseñados antes, la naturalidad, mientras que las intervenciones antrópicas son contempladas como un factor de menoscabo paisajístico, pese a afirmar que "El paisaje de Puente Viesgo se define por la gran incidencia de las actividades ganaderas" (ibidem:25) y que "la ganadería sigue siendo el elemento articulador del paisaje" (ibidem:27). Igualmente, en la Memoria del Plan se dedica un epígrafe al "análisis paisajístico del territorio" en el que se señala que, desde el punto de vista territorial, uno de los tres grandes grupos de componentes del paisaje son las "Actuaciones humanas: diversos tipos de estructuras realizadas por el hombre, ya sean puntuales, extensivas o lineales" (ibidem:48).

En la caracterización paisajística del municipio se ha distinguido una serie de unidades paisajísticas. La herramienta de protección de las mejor valoradas es su clasificación como "Suelo Rústico de Especial Protección" para mantener su integridad; entre ellas los "prados de vega" (por su interés ecológico y su capacidad agrológica) y los "prados de monte" y "pastizales de ladera" (identificados como "terrazgos de monte"). Por el contrario, los "prados de mies", más próximos a los núcleos y con mayor atractivo para la edificación, son calificados como "Suelo Rústico de Protección Ordinaria" a causa de la regresión de su valor agronómico y, sobre todo, por su utilidad para preservar espacio de las construcciones propias de desarrollo urbano, por la inconveniencia de que se den en la ordenación del municipio soluciones bruscas entre el suelo urbanizable y el suelo rústico de especial protección (ibidem:245)

\section{V.1.14. Liendo}

El histórico Valle de Liendo es un municipio, situado en la Marina oriental cuyo núcleo de población principal de nombre elocuentemente agrario, Hazas, dista 51 kilómetros de la capital de la región, Santander, y 55 kilómetros de Bilbao. Esta localización intermedia entre dos áreas urbanas explica el gran crecimiento de su población así como las transformaciones territoriales y paisajísticas derivadas del reciente e intenso proceso de edificación de viviendas, la mayor parte de ellas de uso secundario y vacacional, en relación con la proximidad y gran accesibilidad desde el área metropolitana de la capital vizcaína ${ }^{31}$.

Las áreas de sus mieses o llosas conservan una estructura morfológica tradicional, muy fragmentada, y carecen de desarrollos viarios interiores. Hasta ahora, estas características han constituido un freno a la urbanización de los suelos agrarios y han sido los principales responsables de la preservación parcial de algunos de ellos hasta el presente, aunque empiezan a ser invadidos por las edificaciones en sus bordes más accesibles (Delgado Viñas, 2014a).

31 El número de sus habitantes ha pasado de 811 en 1996 a 1.223 en 2015 (50,8\%) y el de viviendas de 774 en 2001 a 1.031 en $2011(33,2 \%)$ de las que sólo el 48\% son viviendas principales. El crecimiento inmobiliario se había iniciado antes, en relación con la apertura de la autovía del Cantábrico, ya que el parque de viviendas ascendía a 408 en 1991, lo que representa un incremento de 89,7\% hasta 2001 y de $152,7 \%$ desde 1991 a 2011. 


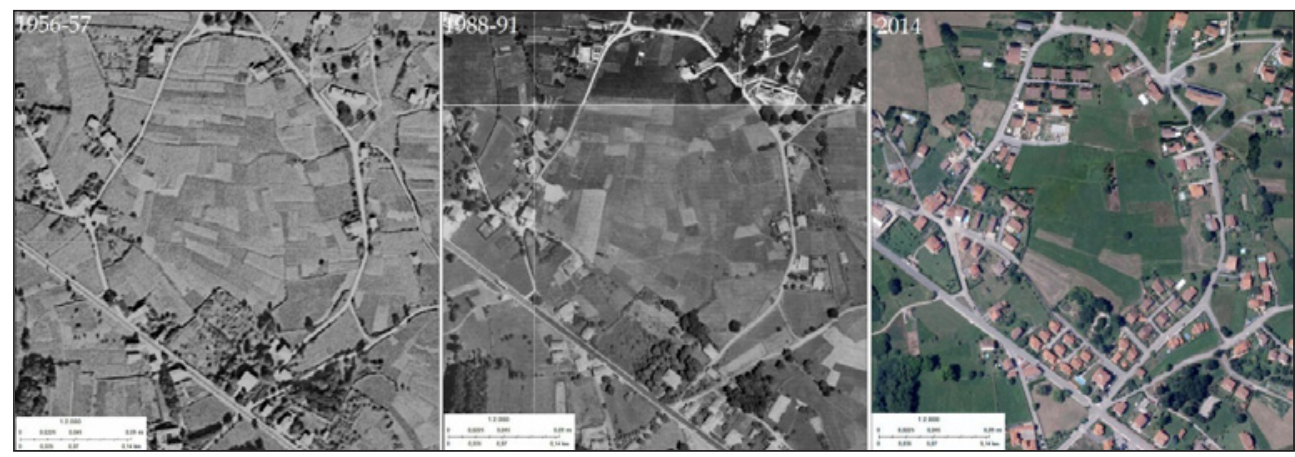

Fuente: elaboración propia a partir de la serie de ortofotografías publicada por la Dirección General de Ordenación del Territorio del Gobierno de Cantabria en el sitio Web http://mapas.cantabria.es/.

El PGOU de Liendo (BOC, 5 de noviembre de 2013, nº 52 extraordinario) otorga una significativa consideración a los terrazgos tradicionales, pero sin identificar ni reconocer su valor como paisajes agrarios. El Plan establece, sin motivarla, la diferencia entre las "Mieses de Protección Ordinaria", normalmente las situadas en el área septentrional del Valle junto al principal eje viario interior, la carretera N-634, y las "Mieses de Especial Protección”, por lo general las localizadas en el sector meridional del término con una deficiente accesibilidad. La justificación argüida para la especial protección de algunas mieses es la necesidad de preservación del paisaje rural y abierto que ofrece panorámicas de enorme singularidad, pero nunca se hace referencia al reconocimiento de su valor patrimonial.

\section{V.2. Los PGOU más sensibles a la consideración del paisaje agrario}

\section{V.2.1. Comillas}

Frente a la nula o escasa atención que les prestan los planes anteriormente comentados, los paisajes agrarios tienen una valoración y protección más importante en otros planes. Como es el caso del PGOU de Comillas (BOC, 3 de septiembre de 2008, $\mathrm{n}^{\circ} 171$ ), un municipio situado en la Marina occidental que, junto a su capital, la histórica villa homónima con funciones más urbanas e intensa y tradicional actividad de veraneo y turística, contiene otros cinco núcleos de población con un carácter plenamente rural ${ }^{32}$.

Desde la perspectiva aquí abordada, entre los objetivos territoriales del PGOU resaltan dos: identificar, delimitar, valorar y potenciar los núcleos rurales existentes en el término, que representan "ejemplos excepcionales de arquitectura del territorio" y "preservar suelo agrario productivo de calidad para la explotación agraria moderna” (Memoria:31).

32 En 2015 la población del municipio asciende a 2.267 habitantes y su parque de vivienda a 2.331 unidades, casi la mitad de las cuales, $1.151(49,4 \%)$, eran viviendas secundarias en 2011. La población del término ha sufrido una pequeña merma desde $1996(-4,1 \%)$ en tanto que el parque de viviendas ha crecido entre 2001 y 2011 un $11,9 \%$, al tiempo que ha aumentado la proporción de viviendas secundarias $(58,4 \%$ en 2001). 
A diferencia de los PGOU antes expuestos, queda de manifiesto algún interés por la preservación de los usos agrarios tradicionales y de los paisajes producidos por ellos, lo que comporta una aproximación al conocimiento genético de los paisajes y una valoración patrimonial implícita, aunque también en este Plan tiene absoluta primacía la consideración esencialmente visual del paisaje.

Para alcanzar dichos objetivos se establece un "Área de Protección Paisajística Agraria Mieses" (valle de Ruiseñada y rasa de Trasvía) en la que no podrán establecerse edificios $\mathrm{u}$ otras construcciones, fijas o temporales, que reduzcan o deterioren la superficie destinada al cultivo y se controlarán las operaciones de concentración parcelaria para «evitar la desaparición de los elementos de organización territorial» (caminos, setos, cercas, cierres, ribazos y bancales..., etc., Normas Urbanísticas:214), procurando mantener la red de caminos existentes y reutilizar los materiales de sus cierres originales. La otra "Área de Protección Paisajística, Caseríos, y Forestal" se encuentra situada al sur del núcleo urbano de Comillas; en ella se exige una parcela mínima de $5.000 \mathrm{~m}^{2}$ en explotaciones con, al menos, 5 ha de superficie total, para edificar viviendas unifamiliares vinculadas a la explotación agraria ${ }^{33}$.

\section{V.2.2. Santillana del Mar}

Un tratamiento similar reciben los paisajes agrarios en el PGOU del cercano municipio de Santillana del Mar, situado también sobre la Marina occidental, que, asimismo, tiene por capital otra villa histórica además de otros nueve núcleos de población de diferentes rasgos y funciones como consecuencia, principalmente, de su proximidad y buena accesibilidad a la ciudad de Torrelavega de la que el núcleo principal dista sólo $9 \mathrm{~km}^{34}$.

De todos los analizados, el PGOU de Santillana (BOC, 7 de mayo de 2004, $\mathrm{n}^{\circ}$ 89) es el que hace referencias más explícitas a los paisajes agrarios desde los primeros párrafos de la Memoria: "el caso de Santillana, en donde la conservación de los rasgos del paisaje agrario constituye uno de los principales valores a preservar" (Memoria, II:121). Por lo que se plantea como objetivo contener "la tendencia actual de edificación de los bordes de la villa, con la grave consecuencia de suponer su aislamiento de un paisaje agrario, cuya inmediatez había constituido, hasta ahora, uno de sus mayores atractivos" (ibidem:13).

Resulta, por ello, lógico y coherente que se consideren como objeto de protección los paisajes agrarios, apreciados, aquí sí, como patrimonio cultural "por su relevancia en la con-

33 Los buenos propósitos de los Planes son, a menudo, contradichos por actuaciones posteriores. Sirva de ejemplo la aprobación de una modificación puntual (la número 3) del Plan General de Ordenación Urbana de Comillas cuyo objetivo es ampliar los límites de suelo urbano en los núcleos rurales de Trasvía, Rubárcena, Rioturbio y Araos - pertenecientes al Parque Natural de Oyambre- al calificar como urbanas varias parcelas rústicas del espacio protegido, como culmen de un proceso iniciado a la par que se aprobaba el PGOU, a partir de las peticiones de varios vecinos que requerían que sus parcelas de suelo rústico se calificasen como urbanas. El Diario Montañés y Europa Press, 5 de diciembre de 2014.

34 La población de Santillana consta de 4.203 habitantes en 2015 y, a diferencia de la vecina Comillas, ha experimentado un aumento de $9 \%$ desde 1996. El parque inmobiliario estaba compuesto en 2001 por 1.429 viviendas (81,8\% principales) y de 1.716 viviendas en 2011 (85\% principales) lo que representa un incremento de $20 \%$. Los datos anteriores permiten concluir que la primacía corresponde sobre todo a la función residencial permanente, como espacio periurbano de Torrelavega. La actividad turística, muy intensa, se apoya esencialmente en las visitas a la villa de corta duración, con finalidades culturales y gastronómicas, más que en la permanencia temporal en residencias secundarias. 
figuración de la identidad del territorio municipal [...] exponentes de la relación establecida a lo largo del tiempo entre la comunidad humana que habita la zona y el medio natural que

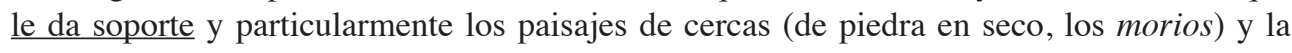
estructura de mosaico de la zona rural" (ibidem).

La calificación del Suelo Rústico de Especial Protección se ha realizado, atendiendo a un conocimiento histórico de la génesis y evolución del paisaje a partir de las aportaciones de un estudio geohistórico anterior (Memoria, I:5 y II:44; Delgado Viñas, 1998), en las siguientes categorías, entre otras:

_ "Forestal y de Pastos" para el "mantenimiento de los montes en su función tradicional [...] cuyo principal valor es la complementariedad de unos especiales valores culturales y paisajísticos" (Memoria, II, pp. 45 ss.).

- "de Prados (abiertos -resultantes de la concentración parcelaria-, cerrados en mosaico, cerrados y aterrazados) que constituyen "el rasgo protagonizador [sic] del paisaje por excelencia" (ibidem).

- "Mieses" (continuas y aterrazadas) protegidas por motivos patrimoniales/paisajísticos y para controlar la excesiva densificación edificatoria. Por ello quedan prohibidos en las mieses todos los usos no vinculados a la actividad agropecuaria "salvo casos excepcionales, como el del pequeño ensanche propuesto para la villa de Santillana" (ibidem).

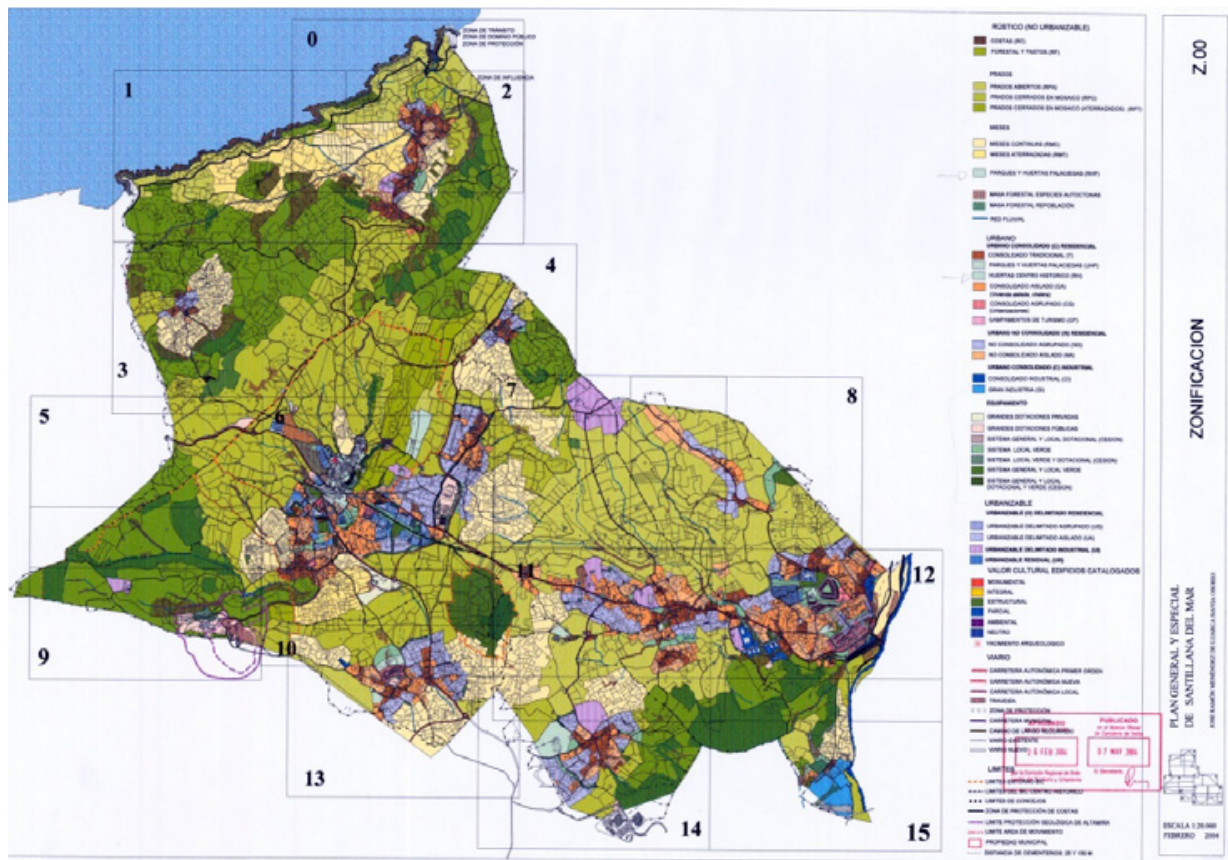

Fuente: PGOU de Santillana del Mar. En amarillo los suelos de las "mieses de especial protección". 


\section{V.2.3. Arnuero}

Arnuero es un municipio situado en la Marina oriental cuyo PGOU fue aprobado en 2013 (BOC, 6 de Noviembre de 2013, $\mathrm{n}^{\circ}$ extraordinario 53). Los principales objetivos y criterios de ordenación son: incrementar la vivienda como lugar de residencia habitual, sobre todo la vivienda social, fomentar la construcción de bloques de vivienda de baja densidad en los núcleos y centros urbanos y la vivienda unifamiliar en las proximidades e, incluso, reducir las edificabilidades que actualmente permite el planeamiento municipal vigente y mantener, como criterio general, la tipología y densidad de población preexistente ${ }^{35}$.

Interesa resaltar el rechazo explícito al modelo territorial anterior "basado en la promoción turística de las playas [... que] produjo una fundamental alteración de la estructura histórica heredada [...]. A partir de esta dinámica se desarrolló posteriormente un fenómeno de aún mayor trascendencia territorial que, basado en un consumo extensivo del territorio, planteó la construcción de un desproporcionado número de viviendas unifamiliares orientadas a la segunda residencia, causando un modelo de ocupación desordenada del paisaje insostenible a medio plazo" (Memoria:3). Frente a éste, el modelo territorial propuesto planea sustituir el patrón de desarrollo "periurbano" (sic) por otro apoyado en los usos residenciales de primera residencia, regulando con prudencia los usos de segunda residencia y su peso en el carácter del municipio.

Adicionalmente, se propone, entre otros fines, promocionar los valores agrícolas, naturales y paisajísticos existentes, proteger los espacios agrícolas y agropecuarios de mayor valía (prados y mieses), potenciando sobre ellos las actividades agropecuarias tradicionales. La herramienta escogida a tal fin es la clasificación como "Suelo Rústico de Especial Protección Agropecuaria» (SREPAg) de los espacios «históricamente dedicados como mieses [...] un paisaje que, alterado y utilizado por el ser humano a lo largo del tiempo, constituyen los terrenos de mayor productividad y potencial agrícola en el municipio, y una referencia histórica de enorme valor patrimonial por ser testimonio del medio económico y cultural del que ha surgido...» (ibidem:13). Se sugiere la dedicación de estos suelos agrarios protegidos al cultivo de productos hortícolas, en particular los pimientos amparados bajo la marca de calidad "Pimientos de Isla".

\section{V.2.4. Cabezón de la Sal}

En 2013 se aprobó también el PGOU de Cabezón de la Sal (BOC, 26 de Diciembre de 2013, $\mathrm{n}^{\mathrm{o}}$ extraordinario 61), un municipio situado en el área prelitoral occidental con 8.353

35 En Arnuero viven 2.125 personas en 2015 y su parque inmobiliario estaba integrado por 2.776 viviendas en 2011, de las cuales 1.607 eran viviendas secundarias $(57,9 \%)$ frente a sólo 847 viviendas principales y 322 vacías. De 1996 y 2015 la población ha crecido en 17,3\% y el parque de viviendas en $28 \%$ de 2001 y 2011. Entre ambas fechas se ha reducido la proporción de viviendas secundarias (70,3\% en 2001) lo que, junto a los datos anteriores, parece indicar el reforzamiento de la función residencial permanente, aunque la secundaria mantenga gran importancia. El Plan calcula una población potencial máxima de más de 12.000 personas, y la posibilidad de acoger otras 7.000 más en los próximos 12 años, por lo que proyecta la posibilidad de edificar 2.140 nuevas viviendas, lo que parece algo contradictorio con el propósito explicitado de moderar el crecimiento inmobiliario. 
habitantes en 2015, la mayor parte de los cuales se concentra en el núcleo homónimo, que funciona como cabecera comarcal de una comarca rural profunda, Cabuérniga, en el valle medio y alto del río $\mathrm{Saja}^{36}$.

El plan, concebido como un "instrumento de ordenación integral del municipio" (Memoria:20), denuncia "La progresiva pérdida de identidad de los núcleos y barrios tradicionales del término municipal, causada por los crecimientos desordenados a lo largo de los ejes viarios existentes" (ibidem:26), al tiempo que destaca la valoración agronómica y paisajística del suelo rústico y declara la "voluntad de volcarse en el suelo rústico con procesos productivos propios del mismo [...] que, aparte la generación de riqueza en estos núcleos, permitirán la conservación de un soporte físico con rasgos plenamente rurales" (ibidem).

En coherencia con lo anterior, en la Memoria del Plan se afirma que "El suelo rústico del municipio conformado por las mieses en las zonas bajas del valle, las praderías y pastizales de zonas intermedias y los montes, [...] supone un importante patrimonio común a mantener. tanto por su propio valor cultural y económico, como por su carácter de signo de identidad paisajística del territorio" (ibidem). Por ello, entre los principales objetivos, plantea el "mantenimiento y refuerzo de los valores patrimoniales indudables" (ibidem:28), lo que no significa un respeto absoluto y reverencial de los terrazgos tradicionales en los casos en que, ya sea la proximidad a núcleos urbanos, ya sea el proceso de extensión de la trama urbana, hacen necesaria la inclusión de los mismos dentro del suelo urbano o urbanizable para su incorporación a los procesos de desarrollo urbano. No obstante, buena parte de los suelos de las mieses, consideradas como entidades territoriales completas, quedan incluidos en la categoría de "Suelo Rústico de Especial Protección Agrícola» y no en la de «Suelo Rústico de Especial Protección Paisajística», que sólo afecta a los espacios cuyos valores naturales medioambientales han sido poco alterados y poseen una alta calidad de percepción y perspectiva visuales, argumentando, de manera parcial y evidentemente sesgada, la vigencia del Convenio Europeo del Paisaje.

\section{V.2.5. Cieza}

También demuestra una especial sensibilidad y concede particular atención a los espacios agropecuarios el PGOU de Cieza (BOC, 14 de julio de 2014, $\mathrm{n}^{\circ}$ extraordinario 33), un pequeño municipio formado por un minúsculo valle lateral de la cuenca del río Besaya y situado en la vía tradicional de comunicación entre el litoral y el sector central de la Montaña Cantábrica ${ }^{37}$.

El Plan distingue y valora las denominadas "Unidades de mieses" y el "Terrazgo de monte", clasificadas unas y otro como "Suelo Rústico de Especial Protección Agropecuaria» «donde los valores y usos agrarios tienen preeminencia sobre otros posibles [...] no tanto en base al valor intrínseco del suelo, generalmente no sobresaliente, como a su tradicional destino ganadero y los consiguientes efectos en la economía y paisaje locales" (Memoria:54).

36 El término municipal ha tenido una ganancia de $18 \%$ de su población desde 1996. Poseía 3.258 viviendas familiares en 2001 (76,6\% principales) y 4.178 en 2011 (74,7\% principales), de manera que el parque inmobiliario ha aumentado $28,2 \%$ entre ambas fechas.

37 En 2015 sus dimensiones se reducían a 560 habitantes (un 22,4\% menos de los que tenía en 1996) y 307 viviendas de las cuales eran principales $244(79,5 \%)$. 


\section{V.2.6. Solórzano}

Similar tratamiento otorga al paisaje el PGOU de Solórzano (BOC, 5 de enero de 2015, $\mathrm{n}^{\mathrm{o}}$ extraordinario 2), un municipio situado en la franja prelitoral de la Marina oriental ${ }^{38}$. El Plan considera el paisaje como un elemento esencial del medio biológico, en particular las unidades denominadas como "el Sistema Pratense que se desarrolla en el poljé de Solórzano y que ocupa la inmensa mayoría del territorio" (Memoria:39-40) y la de "cultivos forestales", correspondiente a la superficie dedicada al cultivo de eucaliptos en las laderas de menor pendiente, en numerosas ocasiones ocupando parcelas anteriormente destinadas a prados de siega.

El Plan señala como uno de los objetivos específicos para el suelo rústico "Reconocer la calidad ambiental como paisaje rural de los espacios no edificados como espacios a conservar [...] favoreciendo la protección y conservación de los recursos patrimoniales que alberga" (ibidem:60). En consecuencia, se clasifican como "Suelo Rústico de Especial Protección Agropecuaria" (SREP-A) "las unidades territoriales de mieses y terrazgos de monte cuyos valores agrarios tengan preeminencia sobre el resto de los posibles valores de los terrenos" (ibidem:80). Además, a diferencia de algunos casos anteriores, ciertos espacios agrarios se incluyen en el "Suelo Rústico de Especial Protección Ecológico-paisajístico" (SREP-EP) que, aunque conformada esencialmente por las superficies arboladas, "También se corresponde con las unidades territoriales de mieses en campos abiertos, en campos cerrados y en bancales; y las de terrazgos de monte en cierros y abertales, cuyos valores paisajísticos tengan preeminencia sobre otros" (ibidem).

\section{V.2.7. Alfoz de Lloredo}

Alfoz de Lloredo es un municipio localizado en la Marina occidental con una población de 2.485 habitantes en 2015 y una dinámica demográfica reciente levemente negativa (-6,1\% desde 1996) pero con una evolución inmobiliaria, por el contrario, creciente ${ }^{39}$. Su proximidad a la ciudad de Torrelavega es considerada decisiva en la configuración actual del municipio por lo que se refiere al empleo de sus habitantes en las fábricas y talleres de aquélla, según se afirma en la Memoria de su reciente PGOU (BOC, 24 de junio de 2015, nº extraordinario 49). Asimismo, algunos de los núcleos de población del municipio se han convertido en espacios residenciales periurbanos de Torrelavega, de primera vivienda en unos casos (Oreña) y de segunda residencia en los más próximos a la costa (Cóbreces).

38 La población del municipio asciende a 1.010 habitantes en 2015 y se ha mantenido prácticamente estancada en los últimos 20 años (-0,4\% desde 1996). El parque de viviendas en 2011 estaba integrado por 551 de las que 375 $(68 \%)$ eran viviendas principales. En 2001 estaban censadas en el municipio 609 viviendas familiares de las que sólo 292 (47,9\%) tenían carácter principal, 134 secundarias y 180 vacías. Si los datos son correctos, cabe entender que el parque de viviendas no se ha incrementado en los 10 años intercensales y que el aumento de vivienda principal lo ha sido a costa del uso de las viviendas vacías. La presencia de varias pequeñas urbanizaciones de viviendas unifamiliares construidas entre 2002 y 2010 en torno a la carretera C-266, en el límite con el municipio de Hazas de Cesto, parece desmentir, aunque sólo sea parcialmente, los datos aportados por los censos.

39 El Censo de Vivienda de 2011 cifra en 1.962 el volumen del parque de viviendas familiares; de ellas eran principales $980(49,9 \%), 731(37,2 \%)$ viviendas secundarias y 251 vacías, si bien la Memoria del PGOU calcula que en 2010 había 2.177 viviendas en el municipio. De acuerdo con los datos censales, entre 2001 y 2011 se habrían construido unas 729 viviendas $(59,1 \%$ del parque en la primera fecha), unas 200 más si son ciertos los datos del PGOU. 
El documento identifica las principales mieses, aunque atribuye incorrectamente su configuración a "la actividad ganadera desarrollada tradicionalmente en esta área [que] ha sido el elemento articulador del paisaje"40 (Memoria:63). En este sentido, se consideran "más valiosos los paisajes representativos de un modelo territorial tradicional, así como aquéllos con los que la población se siente más identificada» (ibidem:72). Si bien, este origen y carácter patrimonial no es el criterio esencial de su preservación, sino que atiende "al concepto de Calidad estética o perceptual, que es la condición que hace que una escena sea apreciada como bella, atractiva, emocionante o evocativa" (ibidem). En relación con estos objetivos, se clasifican como "Suelos Rústicos de Especial Protección” los "Prados de Mies" (REMI) y los "Prados de Monte y Pastizales" (REPM), entre otras unidades territoriales y paisajísticas.

\section{CONCLUSIONES}

En Cantabria, al igual que ha sucedido en otras regiones españolas de forma general, los espacios rurales están sufriendo en las últimas décadas el fuerte impacto de las dinámicas de urbanización extensiva en las áreas litorales, la Marina, y de los procesos de despoblación en las comarcas interiores, la Montaña. Aunque muy diferentes en cuanto a sus causas y características, ambos procesos son responsables del deterioro, cuando no de la desaparición, de espacios y paisajes agropecuarios con alto valor patrimonial. En el primer caso, la transformación descontrolada de los espacios rurales periurbanos, desde la lógica de la expansión urbana dispersa, está provocando la pérdida de los espacios naturales y los paisajes agrarios preexistentes con mayor necesidad de protección.

Estas nuevas circunstancias, en especial a raíz de la elaboración y ratificación del Convenio Europeo del Paisaje, han estimulado una incipiente preocupación por la conservación del paisaje, que se refleja en el reconocimiento del significado medioambiental y económico de los paisajes y que constituye un denominador común en buena parte de los instrumentos cántabros de planificación espacial posteriores al año 2000.

No puede hacerse la misma afirmación en cuanto a la valoración patrimonial del paisaje, en especial por lo que se refiere a los paisajes rurales y, en concreto, a los paisajes agrarios, que, al igual que en otras regiones (Castillo Ruiz y Martínez Yáñez, 2014), rara vez son considerados como un patrimonio colectivo, o con un valor cultural, como paisajes patrimoniales. Probablemente la causa principal, entre otras, sea el desconocimiento de su génesis histórica, la ignorancia involuntaria de los procesos socioeconómicos y culturales que han originado la organización del espacio agrario y los paisajes vernaculares fruto de aquélla. Esta carencia explica, por ejemplo, que los espacios agrarios de las mieses, llosas y erías, incluso cuando son tenidos en cuenta, casi siempre sean entendidos sólo por su valor agronómico, equiparados con otros tipos de terrazgos, como simples espacios de cultivo, sin una apreciación patrimonial similar a la que se otorga a los espacios edificados tradicionales que tienen el mismo origen. Por ende, no parece que esté asimilada socialmente la idea de que los

40 El error consiste en la atribución genética del paisaje de las mieses a la actividad ganadera, cuando ha sido la actividad agrícola tradicional y más antigua, los cultivos, la responsable de la configuración de las mieses ya que los prados sólo empezaron a introducirse en ellas tímidamente a finales del siglo XVIII y, sobre todo, desde mediados del siglo XIX en sustitución de algunos cultivos de cereales y del viñedo, protagonistas de este tipo peculiar de terrazgos durante los siglos anteriores. 
espacios y los paisajes agrarios pueden tener un carácter patrimonial y que, en consecuencia, deben ser protegidos como parte del patrimonio territorial, ni siquiera entre los equipos de expertos redactores de los planes.

No obstante, no cabe duda de que el paisaje está de moda también aquí, por lo que su protagonismo como componente ineludible de las políticas territoriales parece plenamente consolidado (Delgado Bujalance, 2009) y, por ello, puede aseverarse, sin faltar a la verdad, que el marco normativo de Cantabria está empezando a asumir adecuadamente los nuevos enfoques conceptuales del paisaje y su valoración ecológica, social y económica. Así, las alusiones al paisaje se multiplican en la normativa, los planes, informes, dictámenes, declaraciones, reglamentos, etc., aunque, generalmente, se trata de menciones retóricas y, con frecuencia, de exclusivo interés por su aprovechamiento como recurso económico. Pero se trata, en muchas ocasiones, de una concepción generalista del paisaje, naturalista y arquitectónica en el mejor de los casos, que es la que se está trasladando a los instrumentos de ordenación y gestión del territorio que, habitualmente, tienden a identificar el paisaje con los espacios naturales y con el patrimonio cultural edificado, urbanístico y arquitectónico, sin considerar otros valores patrimoniales del territorio, como acertadamente suscribe también Agudo González (2007).

A ello hay que añadir que la creciente presencia del paisaje en la planificación espacial parece asumirse, a veces, de un modo más teórico que práctico. En la mayor parte de los más recientes documentos de planificación cántabros se encuentran referencias al Convenio del Paisaje, pero en la mayoría de los casos no pasan de ser una mención banal que no recoge ni asume que el ámbito de aplicación de dichos documentos es todo el territorio, con independencia de que los paisajes puedan clasificarse como naturales, culturales, rurales, periurbanos o urbanos; se valoren como excepcionales, relevantes, notables o cotidianos; y se consideren como bien conservados o degradados en mayor o menor medida. Por el contrario, se atiende casi siempre a una noción estética del paisaje, vetusta y restringida, identificada con la valoración exclusiva de los paisajes de gran calidad visual. Una consideración, por tanto, alejada del concepto básico del Convenio, que entiende que el paisaje es todo el territorio como es percibido por la sociedad, expresión de la interacción secular de la sociedad y su entorno. Esta concepción de carácter territorial implica la imposible disociación de la gestión del territorio y del paisaje en las políticas públicas de ordenación territorial y urbanística, sin limitarse a la protección y preservación de los paisajes de excepcional belleza, sino también de los demás, incluso los que no son muy atractivos estéticamente.

Por otro lado, con mucha frecuencia se percibe el mantenimiento de una concepción dual del paisaje, natural y cultural, con especial valoración de los paisajes "inalterados", con mayor grado de "naturalidad", y menor apreciación de los paisajes construidos socialmente y aún funcionales, peyorativamente calificados en ocasiones de "intervenidos", resultantes de una hibridación de aspectos naturales y antrópicos.

Muchas de las aproximaciones se limitan a considerar como objeto de valoración los espacios visualmente excepcionales y los espacios escasamente transformados desde una perspectiva de protección ambiental. A lo sumo, se toma en consideración el "patrimonio paisajístico" pero no se les aprecia en su condición de "paisajes patrimoniales" (Gómez Mendoza, 2013). No resulta sorprendente, por tanto, la ausencia de reconocimiento de la necesidad de preservar la actividad agraria como generadora y conservadora de paisajes, y el consiguiente escaso o nulo interés por integrar las actividades agrarias en los documentos de planificación espacial. 
Además de estos aspectos generales, atendiendo a los principales resultados específicos, del estudio minucioso del planeamiento municipal reciente de Cantabria se desprenden situaciones bastante contrastadas. En primer lugar, aunque alguno de los últimos planes hace una somera referencia a la Ley del Paisaje de Cantabria, ninguno de ellos aplica esta norma ${ }^{41}$. Sin tomar en consideración esta última circunstancia, de una parte encontramos los PGOU que prácticamente ignoran la existencia y el valor de los paisajes rurales, en particular de los que califican de "intervenidos" por la sociedad, los que podríamos conceptuar como paisajes culturales propiamente dichos, tanto residenciales como agropecuarios, hasta el punto de que, en muchas ocasiones, la intervención humana es considerada prácticamente como un menoscabo de la calidad paisajística. De otra parte, hallamos un menor número de casos que, con mayor o menor fortuna, otorgan gran importancia a la preservación y gestión de los paisajes culturales, en particular a través de la clasificación de "Suelo Rústico de Especial Protección "y la ordenación normativa de las diferentes categorías establecidas para el mismo.

De hecho, el planeamiento urbanístico municipal se ha convertido en la principal herramienta de intervención sobre el paisaje rural, de su preservación, ordenación y gestión, a pesar de ser un instrumento que apenas se había ocupado hasta ahora de los paisajes, y menos aún de los paisajes rurales cotidianos, residenciales y productivos, agropecuarios y forestales. Por otra parte, rara vez lo hace a través de propuestas explícitas y directas sino que, por el contrario, la primacía corresponde a las actuaciones indirectas, a través de la clasificación del Suelo Rústico de Especial Protección bajo tres enfoques complementarios o alternativos, productivo, ambiental y visual, destacando cada vez en mayor medida el interés por el posible aprovechamiento turístico del paisaje rural.

A pesar de lo cual, se sigue apreciando un deficiente tratamiento, salvo excepciones, de la problemática del suelo rústico, no urbanizable en principio, objeto precisamente de las más recientes reformas legislativas orientadas a allanar la reclasificación del Suelo Rústico de Especial Protección en Suelo Rústico de Protección Ordinaria e, inmediatamente, a facilitar la edificación en este tipo de Suelo. Estos hechos se están repitiendo con mayor asiduidad en los documentos urbanísticos municipales de las áreas periurbanas cántabras, con más presión urbanística y con una notable dinámica de crecimiento poblacional y edificatorio. Aunque, excepcionalmente, participen también de esta «vocación inmobiliaria» los planes de algunos pequeños municipios de montaña, profundamente rurales y con dinámicas demográficas regresivas, que contemplan el incremento del volumen de viviendas para su uso como residencias secundarias como la única alternativa plausible de crecimiento económico. Por otra parte, algunos instrumentos municipales de planeamiento urbanístico (NNSS), aunque afectan a la planificación de todo el territorio municipal, por regla general continúan concediendo especial atención a las áreas de suelo urbano y urbanizable, marginando en muchas ocasiones el suelo rústico. Sin contar con que, hasta hace poco tiempo, muchos municipios rurales no han dispuesto de más instrumentos de ordenación que simples Delimitaciones de Suelo Urbano.

41 Como se señaló antes, aún no se ha terminado de elaborar los instrumentos de desarrollo de la Ley. Por otro lado, no quedan sometidos a las condiciones de la Ley del Paisaje "los planes y proyectos cuya elaboración ya se hubiere iniciado a la entrada en vigor de la presente Ley, siempre que no haya existido una inactividad municipal de impulso de los mismos por un tiempo superior a los dos años" (Disposición Transitoria Única, a). 
Por todas las razones antedichas, y algunas otras que se han ido sugiriendo a lo largo del texto, el tratamiento que suelen recibir los paisajes de la agricultura en los Planes Generales de Ordenación Urbana de Cantabria es todavía muy escaso y, a menudo, adolece, de un enfoque estrictamente agronómico, en relación con el valor del suelo como factor de producción, o, como mucho, de preservación ecológica, más que patrimonial y paisajístico propiamente dichos, hasta el punto de que es frecuente que la protección del paisaje se incluya como una parte o una herramienta de la protección ambiental. Aunque lo importante no es dónde esté incluida sino que esté contemplada la preservación y protección paisajística, sí tiene significación el hecho de que el paisaje no tenga una consideración por sí mismo sino como elemento ambiental.

De ahí la necesidad de completar el desarrollo de las leyes específicas de paisaje con unas directrices claras que sirvan de referencia a los organismos e instancias administrativas, con responsabilidad y capacidad de decisión en este asunto, sobre el significado y las formas de ordenar el territorio y el paisaje, que obliguen al planeamiento urbanístico a respetar unos mínimos denominadores comunes, de forma homogénea como hace el POL para el ámbito litoral, y que eviten actuaciones de ordenación, protección y gestión contradictorias entre unos municipios y otros.

Como punto de partida, un elemento decisivo debería ser el conocimiento científico, histórico y geográfico, de la construcción social de los paisajes, su origen y evolución, indispensable para su reconocimiento y valoración como patrimonio sociocultural. Asimismo, tiene gran trascendencia la propia composición de los equipos redactores de los instrumentos de planificación, su carácter multidisciplinar y, en concreto, la presencia de profesionales del territorio, geógrafos y geógrafas entre otros, que se revela claramente en la sensibilidad con que se trata el territorio y en el enfoque conceptual, más genético o únicamente visual, con que se abordan los aspectos paisajísticos. No en balde, el Convenio argumenta la necesidad de establecer programas universitarios multidisciplinares para la formación de expertos en el conocimiento de los valores propios del paisaje y de todos los aspectos relativos a su protección y gestión.

\section{REFERENCIAS BIBLIOGRÁFICAS}

AGUDO GÓNZÁLEZ, J. (2007): «Paisaje y gestión del territorio». Revista Jurídica de la Universidad Autónoma de Madrid, $\mathrm{n}^{\circ}$ 15, 197-237.

BERTRAND, G. (1994): Le paysage: un outil pour l'aménagement des territoires. MidiPyrénées, CESR (Conseil Économique et Social Régional de Midi-Pyrénées).

CAÑETE PÉREZ, J.A. (2015): «La actividad agraria en la planificación territorial y urbanística» en Castillo Ruiz, J. et alii: El patrimonio agrario: la construcción cultural del territorio a través de la actividad agraria, Sevilla, Universidad Internacional de Andalucía, 321-354.

CASTILLO RUIZ, J. y MARTÍNEZ YÁÑEZ, C. (2014): «El patrimonio agrario: definición, caracterización y representatividad en el ámbito de la UNESCO». Boletín de la Asociación de Geógrafos Españoles, $\mathrm{n}^{\circ}$ 66, 105-124.

DELGADO BUJALANCE, B. (2009): "Los paisajes periurbanos en los planes subregionales de las aglomeraciones urbanas andaluzas: logros, carencias y contradicciones". Boletín de la Asociación de Geógrafos Españoles, nº 49, 105-128. 
DELGADO VIÑAS, C. (1998): Santillana del Mar. La evolución milenaria de un espacio rural cántabro. Santander, Ed. Estvdio.

DELGADO VIÑAS, C. (2010): "La ordenación territorial en Cantabria: normas, planes, proyectos y realidades". Cuadernos Geográficos, n 47, 453-491.

DELGADO VIÑAS, C. (2014a):“Espacios rurales y paisajes agrarios del litoral cantábrico. El valle de Liendo en la Marina Oriental de Cantabria”. Ería. Revista cuatrimestral de Geografía, no 93, 43-75.

DELGADO VIÑAS, C. (2014b):“Los paisajes rurales en los instrumentos recientes de gestión territorial en Cantabria (España)" en De la geografía rural al desarrollo local, León, Universidad de León, 367-387.

DELGADO VIÑAS, C. (2015): "El paisaje rural y agrario en los instrumentos de ordenación y protección territorial. El caso de Cantabria (España)" en Enjeux territoriaux, jeux d'acteurs et interdisciplinarité, Aix-en-Provence (France), CNRS Aix-Marseille, 41-56

ESPAÑOL ECHÁNIZ, I. (2010): "El paisaje como nuevo paradigma de la sostenibilidad". Fabrikart, n ${ }^{\circ}$ 9, 104-115.

GARCÍA GARCÍA, M. y BOROBIO SÁNCHIZ, M. (2012): "El paisaje como medio para la planificación territorial". Ciudades, $\mathrm{n}^{\circ} 15,115-132$.

GÓMEZ MENDOZA, J. (2013): "Del patrimonio paisaje a los paisajes patrimonio”. Documents d'Anàlisi Geogràfica, vol. 59/1, 5-20.

MATA OLMO, R. y TARROJA i COSCUELA, A. (Coord.) (2006): El paisaje y la gestión del territorio: criterios paisajísticos en la ordenación del territorio y el urbanismo. Barcelona, UIMP- Diputación de Barcelona.

MATA OLMO, R. et alii (2012): "Sustainable development and the making of territory and everyday landscapes as heritage-an experience in the Cantabrian mountains" en Territorial Heritage and Development. Leiden, Taylor and Francis Group, 141-158.

MULERO MENDIGORRI, A. (2013): "Significado y tratamiento del paisaje en las políticas de protección de espacios naturales en España". Boletín de la Asociación de Geógrafos Españoles, $\mathrm{n}^{\circ}$ 62, 129-145.

SÁNCHEZ del ÁRBOL, M.A. (2015): "Espacios naturales protegidos y patrimonio agrario" en Castillo Ruiz, J. et alii: El patrimonio agrario: la construcción cultural del territorio a través de la actividad agraria, Sevilla, Universidad Internacional de Andalucía, 269-320.

SILVA PÉREZ, R. (2010), “Tratamiento normativo de los paisajes agrarios españoles”. Anales de Geografía, vol. 30, $\mathrm{n}^{\circ} 1,119-138$.

SIMÓN ROJO, M., ZAZO MORATALLA, A. y MORÁN ALONSO, N. (2012): "Nuevos enfoques en la planificación urbanística para proteger los espacios agrarios periurbanos". Ciudades, $\mathrm{n}^{\circ} 15,151-156$.

ZOIDO NARANJO, F. (Coord.) (2015): El paisaje en la práctica de la ordenación del territorio. Análisis, propuesta metodológica y aplicación práctica a partir de los planes de ámbito subregional de Andalucía. Sevilla, Centro de Estudios Paisaje y Territorio/ Universidad de Sevilla. 
